\title{
Improving College Access and Success for Low-Income Students: Evidence from a Large Need-based Grant Program*
}

\author{
Gabrielle Fack \\ Universitat Pompeu Fabra and Barcelona GSE \\ Julien Grenet \\ Paris School of Economics
}

First Draft: October 2012

This Draft: September 2013

\begin{abstract}
Using comprehensive administrative data on France's single largest financial aid program, this paper provides new evidence on the impact of large-scale need-based grant programs on the college enrollment decisions, persistence and graduation rates of low-income students. We exploit sharp discontinuities in the grant eligibility formula to identify the impact of aid on student outcomes at different levels of study. We find that eligibility for an annual cash allowance of 1,500 euros increases college enrollment rates by up to 5 percentage points. Moreover, we show that need-based grants have positive effects on student persistence and degree completion.
\end{abstract}

JEL Classification: H52, I22, I28, J24, J38

Keywords: Need-based grants; college enrollment; student persistence; degree completion

*Mailing address: Paris School of Economics, 48 bd Jourdan, 75014 Paris, France. Email: julien.grenet@ens.fr and gabrielle.fack@upf.edu. The authors are grateful to Frédéric Brouillet, Laurence Dauphin, Olivier Lefebvre, Jean-Yves de Longueau, Bruno Lutinier, Hélène Michaudon and Ophélie Rogel from the French Ministry of Higher Education for their precious help in collecting the data. This work was financially supported by the CEPREMAP. Gabrielle Fack acknowledges support from the Spanish Ministry of Science and Innovation through the grant ECO200912157. The author thank seminar participants at Paris School of Economics, Universitat Pompeu Fabra, Universidad de Alicante, University of Bristol, University of Sussex, CEMFI, CREST, Uppsala University, and conference participants at the CEPR Public Policy Symposium 2013 and EEA/ESEM 2013 for their helpful comments. An earlier version of this work was circulated under the title "Means-Tested Grants and Students' Higher Education Decisions in France: a Regression Discontinuity Approach". 


\section{Introduction}

Access to higher education has increased substantially over the past two decades. Between 1995 and 2010, university entry rates rose from 37 to 62 percent on average across OECD countries. Despite this widening of participation in higher education, young people with low educated parents are still less than half as likely to be in higher education compared with their peers in the general population (OECD, 2012). These differences in educational attainment translate into persistent earnings inequalities.

To lower the financial barriers to post-secondary education for low-income students, many countries operate broad-based financial aid programs that provide tuition waivers and cash transfers. These programs are typically needbased, with awards decreasing in parental income and capped at around 6,000 dollars. Examples of such schemes include the Maintenance Grant in the UK, the Spanish Becas, the Pell Grant in the US and the French Bourses sur critères sociaux (hereafter BCS). All these programs are nationwide and cover a nonnegligible fraction of the student population - up to a third in the US and in France.

Despite the central importance of large need-based financial aid programs in promoting equal access to higher education, and considering the financial stakes involved, relatively little is known about their effectiveness in improving the outcomes of low-income students. This paper aims to fill this gap by providing a comprehensive assessment of France's single largest need-based grant program. We take advantage of the existence of sharp discontinuities in the BCS grant eligibility formula to estimate the impact of financial aid on college enrollment, persistence and degree completion rates for low-income students.

The assessment of need-based grant programs requires going beyond evaluating their impact on college enrollment decisions, since the ability of such programs to improve the educational and labor market outcomes of low-income students ultimately depends on how they affect persistence and degree at- 
tainment. Standard models of human capital investment with borrowing constraints predict that the provision of financial support should increase initial enrollment rates by lowering the cost of college. ${ }^{1}$ The enrollment effects of need-based grants are therefore entirely determined by the behavior of the "marginal" students, i.e., of those who would not have attended college without financial support. In contrast, their impact on persistence and degree completion rates depends on the behavioral responses of both the "marginal" and the "inframarginal" students, the latter group referring to students who would have attended college irrespective of their eligibility for a grant. If marginal students are of substantially lower average ability than inframarginal students, then need-based grants might have only a weak impact on persistence and degree completion rates. The provision of financial support could, however, improve the learning conditions of all students by allowing them to work less, to be more focused on their studies and to eventually complete a degree. ${ }^{2}$ Because the combined effect of these "extensive" and "intensive" margin responses is uncertain, the overall impact of financial assistance programs on student persistence and degree attainment is fundamentally an empirical question.

The literature on student aid provides relatively little direct empirical evidence on the impact of large need-based programs on college access and success for low-income students. Most of the existing work focuses on more narrowly defined programs, which have been implemented in the US for specific groups of students and/or are operated at the level of a particular state or university. Examples of such programs include the Veterans' educational benefits (Angrist, 1993; Stanley, 2003; Bound and Turner, 2002, 2003), the Social Security Student Benefit Program (Dynarski, 2003) and a variety of state merit-based

\footnotetext{
${ }^{1}$ The importance of college costs in students' educational choices is further emphasized in models that take into account the role of risk aversion in the demand for education (Brodaty et al., 2012).

${ }^{2}$ Many students are constrained to work to fund their studies, which can have adverse effects on their college attainment. In France, over 20 percent of students work on a regular basis during the academic year (OVE, 2011) and recent empirical evidence suggests that holding a regular part-time job has large detrimental effects on the probability of graduating from college (Beffy et al., 2013).
} 
programs targeted at students who meet certain academic requirements, ${ }^{3}$ or at students who are already in college (Angrist et al., 2009; Goldrick-Rab et al., 2012), as well as state need-based grant programs which supplement federal aid (Castleman and Long, 2012). To overcome the identification issues that arise when estimating the impact of financial aid on student outcomes, the standard practice has been to use policy changes and eligibility rules as sources of exogenous variation to identify the parameters of interest. Most of the above studies find that the provision of financial support has a positive impact on the targeted groups' college enrollment decisions and a few papers also find positive effects on college attainment. It is, however, unclear whether these results would apply to broader need-based grant programs, which typically serve larger populations and are only awarded on the basis of students' financial need.

In contrast to this vast body of research, the available evidence on the effects of large-scale need-based programs appears both limited and mixed. A number of authors have investigated the effects of the aforementioned Pell Grants, with a specific focus on initial enrollment decisions and choices amongst colleges. Overall, existing studies find no clear and persuasive evidence that Pell Grants significantly impact college access for the marginal, low-income students. ${ }^{4}$ To our knowledge, Bettinger (2004) is the only paper to examine the effect of Pell Grants on student persistence between the first and second year of college, using discontinuities in the eligibility formula. ${ }^{5}$ His estimates suggest that

\footnotetext{
${ }^{3}$ Studies include Dynarski (2000, 2008), Abraham and Clark (2006), Cornwell et al. (2006), Kane (2007), Goodman (2008). For a review, see Deming and Dynarski (2010).

${ }^{4}$ For a review of empirical studies on the Pell Grant program, see Kane (2006), Deming and Dynarski (2010), and also Kane (1995) and Seftor and Turner (2002). Some studies have explored specifically the complexity of the Pell Grant Program (Dynarski and Wiederspan, 2012; Dynarski and Scott Clayton, 2008; Bettinger et al., 2012) and its inflationary effect on tuition fees (Goldin and Cellini, 2012; Turner, 2012) as potential explanations for its limited impact on college enrollment. In the French context analyzed in this paper, such a phenomenon is unlikely to occur since most higher education institutions are not free to set their own tuition fees.

${ }^{5}$ Castleman and Long (2012) also use discontinuities to evaluate the impact of grants on degree completion rates, but they consider a program (the Florida Student Access Grant) which supplements Pell Grants. They estimate the effects of this additional subsidy on student outcomes but not the impact of the initial Pell Grant (i.e., of some aid versus no aid).
} 
Pell Grants tend to reduce dropout rates but the findings are not completely robust to specification. Empirical evidence on the impact of need-based grant programs outside of the US is even more limited and mixed. ${ }^{6}$ In these latter studies, the reliance on indirect sources rather than on direct administrative data on grant applicants has typically prevented researchers from exploiting small variations in grant eligibility formulas to identify the programs' effects on student outcomes.

Our paper makes several contributions to the literature on student financial aid. First, we are able to link administrative micro-data on the universe of students applying for need-based grants in French higher education over the period 2008-2010 with data on all students enrolled in French public universities. These administrative data allow us to exploit sharp discontinuities in the assessment formula to estimate the impact of grant eligibility on student outcomes without having to be concerned about student mobility across institutions. Second, our analysis takes advantage of the fact that grant applications have to be renewed every year to estimate the effect of financial aid on applicants' decisions at each level of study, i.e. for those entering college as well as for those who are already enrolled in higher education. Third, we investigate the impact of financial aid on a broader set of outcomes than most previous studies have been able to examine, analyzing not only college enrollment decisions, but also persistence and degree completion rates.

We find that being eligible for a cash allowance of 1,500 euros per year increases college enrollment or re-enrollment rates by up to 5 percentage points. Moreover, our estimates show that the effects of need-based grants are not short-lived since eligibility for the cash allowance has a positive and significant impact on the persistence rates of prospective undergraduate and graduate students. The effects on degree completion are more mixed. While being eligible for an allowance of 1,500 euros is not found to significantly increase the

\footnotetext{
${ }^{6}$ See Nielsen et al. (2010) for the Netherlands; Steiner et al. (2006; 2011) for Germany; Dearden et al. (2011) for the UK.
} 
probability of graduating on time for college entrants, our estimates point out to positive and significant degree completion effects for continuing students, of 5 percentage points for prospective master's students, and of up to 3 percentage points for students in their final year of an undergraduate or graduate degree program.

At a time of historic budget shortfalls, the cost-effectiveness of large-scale financial aid programs is being increasingly questioned. We interpret our findings as evidence that such programs can improve the educational outcomes of low-income students, both on the extensive margin of college going and on the intensive margin of academic achievement in university. Our results suggest, however, that the net social benefits from need-based grant programs are larger for continuing students than for college entrants.

The remainder of this paper is as follows. Section 2 provides some institutional background on French higher education and outlines the main features of the BCS grant program. Section 3 explains the estimation strategy. Section 4 describes the data. Section 5 discusses the validity of the regression discontinuity design, presents the main results and performs a number of robustness checks. Section 6 concludes.

\section{Institutional Background}

In this section, we provide a brief overview the French system of higher education and detail the costs of college education in France. We next turn to the description of the main features of the BCS need-based grant program.

\subsection{Higher Education and the Cost of College in France}

The French system of higher education comprises various institutions, the vast majority of which are publicly funded. ${ }^{7}$ After graduating from high school, stu-

\footnotetext{
${ }^{7}$ In 2010-2011, private institutions accounted for less than 18 percent of total enrollment in higher education (MEN, 2013).
} 
dents willing to engage in post-secondary education can choose between two main tracks. Out of the of 78 percent of high school graduates who decide to enter higher education, ${ }^{8}$ the majority chooses to enroll in public universities (56 percent), which offer academic and vocational undergraduate degrees (mainly three-year degrees called Licence), graduate degrees (Master) and doctoral degrees. French universities are not selective as the only requirement for undergraduate admission is to have passed the high school graduation exam (Baccalauréat). About a third of the high school graduates who enter higher education choose instead to enroll in special public high schools which offer two types of courses: academically-oriented courses preparing for admission to elite graduate schools (Classes Préparatoires aux Grandes Écoles) or professionallyoriented courses leading to advanced vocational degrees (Sections de Technicien Supérieur). Admission to either type of course is selective as there are only a limited number of seats available for each program. Outside of these two main tracks, a minority of high school graduates choose to enroll in specialized public or private higher education institutions that lead to specific degree programs (such as schools of art, architecture, journalism, etc.).

In France, the costs of post-secondary education are mainly driven by living expenses, since tuition fees in public universities are set at a very low level (in 2010, annual tuition fees were 174 euros for undergraduate students and 237 euros for graduate students). Living costs incurred by students can, however, be relatively high, as most higher education institutions are located in large cities. Subsidized university residence halls are in very limited supply and housing costs in the private sector can be substantial in some areas, even after taking into account the housing benefits for which most students are eligible if they live away from home. Recent surveys on students' social and economic conditions indicate that on average, college students living away from home spend around 700 euros per month to cover their living expenses. In addition, students have to pay annual tuition fees and social security contributions (around $200 \mathrm{eu}-$

\footnotetext{
${ }^{8}$ The figures refer to the academic year 2010-2011.
} 
ros per year). According to our computations, the total average budget for a nine-month academic year amounts to 6,300 euros, representing a potentially important barrier to low-income students' access to higher education. ${ }^{9}$

\subsection{The BCS Need-Based Grant Program}

The Bourses sur Critères Sociaux program is France's national financial support scheme for low-income students at the post-secondary level. About a third of students enrolled in higher education receive a BCS grant, for a total cost of 1.7 billion euros in 2010. Other forms of financial support, such as State guaranteed student loans or merit-based grants, which exist on a large scale in many countries, are almost non-existent in France. ${ }^{10}$

The amount of financial aid awarded through the BCS program depends on applicants' parental taxable income and a composite score which takes into account their number of siblings and the distance between their parents' home and the university they plan to attend. The program consists of seven levels of grants (referred to as échelons), which range from 0 to 6 . Students who qualify for a level 0 grant are exempt from paying tuition fees (if they attend a public university) and social security contributions, but are not eligible for cash benefits. In addition to the fee waivers, students who qualify for a level 1 grant receive an annual cash allowance of approximately 1,500 euros, which we estimate to cover a third of the average living expenses of eligible students who live away from home. ${ }^{11}$ This annual allowance increases by smaller increments at each of the higher levels of grant (the average increment being 600 euros) up to a maximum of 4,200 euros per year for a level 6 grant, which would

\footnotetext{
${ }^{9}$ The details of the calculations are provided in the paper's online appendix (www.parisschoolofeconomics.com/grenet-julien/Articles/FackGrenet2013appendix.pdf)

${ }^{10} \mathrm{~A}$ program of State guaranteed loans was introduced in 2008 but with very limited success, since less than 0.3 percent of students in higher education contracted such loans over the first three years of the program. Publicly provided merit-based grants exist but are awarded each year to less than 1,000 undergraduate and graduate students who already qualify for need-based grants.

${ }^{11}$ See the online appendix for details on the calculation of the share of living expenses covered by the different levels of BCS grant.
} 
cover 90 percent of the eligible student's average living expenses. The amounts awarded through the BCS program can therefore be regarded as significantly reducing the cost of college education for low-income students.

Our estimation strategy takes advantage of the multiple discontinuities that are created by the grant eligibility formula to estimate the impact of qualifying for different levels of grant on applicants' outcomes. We detail below the program's eligibility rules and review the application process, emphasizing the features which limit the applicants' ability to manipulate the assignment variables around the eligibility thresholds.

\subsubsection{Eligibility Rules}

Eligibility to a BCS grant is conditional on applying for a full-time degree program at a French higher education institution and on being under 29 years of age at the time of application. ${ }^{12}$ The level of grant to which applicants are entitled is a deterministic function of their parental income and of a discretevalued family needs assessment (FNA) score called points de charge. Parental income is the taxable income that appears on the tax notice that the applicant's parents received in the year preceding the application and corresponds to the amount of taxable income that they earned two years before. ${ }^{13}$ During the period covered by our analysis (2008 to 2010), the FNA score was computed on the basis of two criteria: i) number of siblings and ii) distance to university. ${ }^{14}$ Each sibling counts for four points if he/she registered in higher education at the time of application and for two points otherwise. Extra points are awarded to applicants whose parents' home is located more than $30 \mathrm{~km}$ away from the chosen university, one point up to $249 \mathrm{~km}$ and two points beyond. The points

\footnotetext{
${ }^{12}$ Eligibility rules are detailed in the Circulaire 2009-1018 du 2-7-2009, Bulletin officiel de l'Education Nationale $n^{\circ} 30$ du 23 juillet 2009.

${ }^{13}$ When parents are divorced or single, applicants are requested to report the taxable income of the custodial parent's household.

${ }^{14}$ In 2008, the French ministry of Higher Education decided to no longer take into account other criteria that were previously used in the computation of the FNA score (such as single parent status or student disability).
} 
for siblings and distance to university are added together to compute the FNA score, which is capped at 17 points. The median score among applicants is 3 points.

The parental income thresholds that determine eligibility to the different levels of grant depend on the applicant's FNA score, generating multiple discontinuities. Figure 1 provides a graphical representation of the full set of income eligibility thresholds that were used in the 2009 round of applications, whereas Figure 2 shows the amount of cash allowance for which a 2009 applicant with an FNA score of 3 points would qualify depending on her parental income. This applicant would not be eligible for any level of grant if her parental income was above 46,145 euros, placing her family in the top quintile of the income distribution of household income in France. ${ }^{15}$ To be entitled to the highest level of grant (level 6), her parental income would need to be below 10,509 euros, which corresponds approximately to the bottom quintile of the household income distribution.

As most large-scale need-based grant programs around the world, the BCS scheme awards grants on a yearly basis. Grants can be renewed up to seven times but students are required to file a new application every year, their parental income and FNA score being reassessed each time. In addition, grant renewal is subject to minimum academic achievement requirements. Grant recipients loose their right to a grant if they fail to obtain 60 credits (which is the number of credits obtained in a typical university year) two years in a row. In other words, grant renewal is suspended after two consecutive failures in a given year level. Eligible students are also required to comply with the attendance requirements set by their university and to take all of the exams. Failure to meet these requirements may lead to the repayment of the allowance received by the student. ${ }^{16}$

\footnotetext{
${ }^{15}$ Source: authors' calculations based on the Enquête Revenus Fiscaux et Sociaux 2008. All amounts are expressed in 2011 euros.

${ }^{16}$ Unfortunately, the extent to which these regulations are enforced in practice cannot be measured from our data. This is because the exact reason for why certain applicants are denied a conditional grant despite being eligible on the basis of their parental income and
} 


\subsubsection{Application Process}

The grant application process for students who are planning to enroll or to reenroll in a higher education institution begins in the January preceding the start of the academic year and spans over several months. Individual applications are processed by the regional branches of the national student service agency (CNOUS). The main application steps can be summarized as follows.

(i) Official online application round (January 15 - April 30). Students apply jointly for need-based grants and student housing (optional) on a dedicated website. ${ }^{17}$ They can submit up to four pre-registration applications, as they may not yet have made a definitive choice regarding the institution or degree program that they plan to attend at the start of the next academic year.

(ii) Processing of applications (May 1 -Mid-July). Individuals applications are processed by the local branch of the student service agency upon reception of all supporting documents. The grant schedule is updated in early July, after which applicants receive a conditional grant notification, which indicates the level of grant for which they can qualify for each of their pre-registration choices.

(iii) University registration and payment of cash allowance (Mid-July onwards). The academic enrollment process begins in mid-July and lasts until the end of September. Upon proof of registration, grant recipients start receiving the first of their nine monthly payments in October and receive the final grant payment in June of the following year.

Two key features of the BCS program limit the applicants' ability to manipulate the information provided to the student service agency in order to qualify for higher levels of grants than they would normally be entitled to. First, the exact values of the income thresholds that determine the amount of financial support for a given FNA score are unknown to candidates when they

FNA score is not specified. These grounds include not only the non-compliance with the minimum academic achievement requirements but also the withdrawal of some applications or the failure to send all the supporting documents to the student service agency.

${ }^{17}$ https://dse.orion.education.fr/depot/. 
submit their application. To get a rough idea of the amount of grant for which they would qualify, they can rely on an online simulator which is based on the current year thresholds ${ }^{18}$, and not on the actual schedule that will be used to assess their eligibility. The income thresholds are updated in early July and their new values cannot be precisely inferred from the previous ones, since the adjustment usually goes beyond the inflation factor. The ability to predict the values of the new thresholds is further complicated by the fact that the online simulator does not explicitly provide the values of the current thresholds, but computes instead the amount of grant based on the user's stated parental income and FNA score. In light of these practical aspects of the application process, it seems unlikely that applicants would have sufficient knowledge to accurately predict how far away they will be from the new thresholds.

The second key obstacle to manipulating the information that enters the financial aid award formula is that applicants are required to submit all supporting documents for their grant application. The only admissible proof of parental income is a paper copy of the applicant's parents' tax notice, which they received in the year immediately preceding the application. The tax notice is also used to determine the number of dependent children in the applicant's family. The points awarded for siblings enrolled in post-secondary education at the time of application are conditional on the submission of their university enrollment certificates. Finally, the distance between the parents' home address (as shown on the tax notice) and the chosen university is computed by the student service agency's geolocation tool.

Not only is the scope for manipulation of the grant eligibility criteria limited, but it is also very unlikely that the updated income thresholds would influence the decision of whether or not apply for a grant, since these thresholds are unknown until applications have been fully processed. Moreover, it should be

\footnotetext{
${ }^{18}$ http://www.cnous.fr/_vie__dossier_264.757.265.htm. Users of this online simulator are informed that changes in the grant schedule can affect the level of grant to which they will ultimately be entitled. They are further advised that they should apply for a grant even if they are uncertain about their eligibility.
} 
noted that students have an incentive to submit an application even if their parental income falls above most of the thresholds set by the BCS schedule, because they would remain eligible for some form of financial support. Indeed, all students who qualify for a grant of level 0 or above are at least eligible for fee waivers. It is therefore in their interest to file an application even if they do not qualify for the annual cash allowance. The only income thresholds that are associated with a clear change in incentives to submit an application are those that determine eligibility for a level 0 grant as opposed to no grant a all. Around these thresholds, the number of applications can be expected to decrease rapidly as a function of parental income. However, as long as students cannot predict the exact location of the new thresholds, this decreasing pattern should be continuous. This issue will be examined in more detail in section 5.1.

\section{Data and Descriptive Statistics}

Our analysis is based on linked individual-level administrative data that allow us to track the enrollment decisions and academic progress of all prospective college students who filed an application for a BCS grant.

We combine three main administrative data sources, which were provided to us by the Statistical office of the French ministry of Higher Education (MESRDGESIP) and were matched using an encrypted student identifier: (i) AGLAE, which covers the universe of applicants to BCS grants over the period 2008 to 2010; (ii) SISE, which includes all students enrolled in public universities in academic years 2008-2009 through 2010-2011; and (iii) OCEAN, which provides the high school graduation exam (Baccalauréat) scores of all high school seniors between 2003 and 2010 .

The AGLAE data contain basic information on the socio-demographic characteristics of BCS grant applicants (gender, age, place of residence, etc.), the full set of variables that determine grant eligibility (including their parental income and FNA score), the amounts of conditional and final grant awarded 
as well as the degree program attended by the student (for grant recipients only). The SISE dataset covers approximately two thirds of students enrolled in higher education (i.e., all students attending academic or vocational courses in publics universities), and contain basic information on the socio-demographic characteristics of students, detailed information on the university, name and year level of the degree program they attend, and a binary variable indicating whether they successfully completed the degree. For the academic year 20102011, we supplement the SISE data with an extract of the Base Centrale de Scolarité, which includes the universe of undergraduate students enrolled in selective post-secondary vocational education or in preparatory classes to elite schools. Finally, we use the OCEAN data ro retrieve individual-level information about the high school graduation results of applicants to BCS grants, which are converted into percentile ranks for each cohort of high school seniors.

In order to be able to track the college enrollment decisions of BCS grant applicants, we restrict our sample to applicants who listed an undergraduate or a graduate college degree program for each of their pre-registration choices (62 percent of all applicants) and who submitted their application before July, i.e., before the update of the income thresholds ${ }^{19}$. We further exclude from the sample high school applicants who ended up being ineligible for a BCS grant because they failed to pass the Baccalauréat exam. Finally, we drop the small fraction of applicants (13 percent) whose FNA score varies across their preregistration choices through the points awarded under the distance to university criterion, to avoid the complexities induced by the fact these applicants can be eligible for different levels of grant across their different choices. ${ }^{20}$

Table 1 presents some descriptive statistics on our sample of BCS grant applicants, which we split into three groups: i) The "L0/No grant cutoffs" sample (column 1) includes applicants whose parental income is close to the eligibility thresholds between no grant and a level 0 grant (fee waivers only);

\footnotetext{
${ }^{19}$ Although some late applications are accepted by the student service agency, they represent less than 14 percent of all applications.

${ }^{20} \mathrm{In}$ practice, including these applicants yields similar results.
} 
ii) the "L1/L0 cutoffs" sample (column 2) includes applicants in the vicinity of the income thresholds between level 0 and level 1 grants, where students become eligible for an additional cash allowance of 1,500 euros per annum; iii) the "L6/L5 to L2/L1 cutoffs" sample (column 3) pools applicants who are close to the income thresholds between two consecutive levels of grant in the level 2 to level 6 range, where the amount of annual cash allowance increases by 600 euros on average. The table shows that with an average Baccalauréat percentile rank of about 60 , BCS grant applicants tend to be of higher academic ability than the average high school senior in their cohort. The high proportion of female applicants (around 60 percent) reflects the fact that in France, female students are both more likely to enter higher education and to attend nonselective colleges than males. Approximately 75 percent of applicants in our sample are prospective first to third year undergraduate students while the remaining 25 percent are prospective first or second year master's students. By construction, the average parental income of applicants in the "L6/L5 to L2/L1 cutoffs" sample (21,669 euros) is lower than that of applicants in the other two samples (31,632 euros for the L0/L1 sample and 42,068 euros for the L0/no grant sample). They also tend to have more siblings, which explains their higher FNA score.

\section{Empirical Strategy}

We use a regression discontinuity design to estimate the impact of need-based grants on applicants' higher education outcomes. Our approach takes advantage of the existence of sizable discontinuities in the amount of financial aid that applicants can receive depending on their parental income and FNA score.

Our goal is to estimate the causal effect of being eligible for a need-based grant on the outcomes of applicants:

$$
y_{i}=\alpha+\beta \cdot G_{i}+u_{i}
$$


where $y_{i}$ is the outcome of interest for applicant $i$ (e.g., being enrolled in college), $G_{i}$ is a dummy variable equal to one if the applicant is eligible for a need-based grant and zero otherwise, and $u_{i}$ is the unobservable error term. A simple OLS regression of equation (1) would yield a biased estimate of $\beta$ because grant eligibility is partly determined by parental income, and therefore endogenous. Even after controlling for family income, OLS estimates could be biased due to the endogenous selection of applicants. Since not all eligible individuals participate in the program, the decision to apply for a grant is likely to be correlated with unobservable characteristics that affect the outcomes of interest.

In order to identify the treatment effect of being entitled to a grant, we exploit the fact that the BCS grant eligibility formula creates discontinuities in the amount of financial aid awarded to applicants. The intuition behind our empirical strategy is the following. Since the income thresholds between different levels of grant are exogenously given, and assuming that the information provided to the national student service agency cannot be precisely manipulated by applicants, we can focus on applicants who are in the vicinity of a threshold, and consider that those just below are very similar to those just above. The amount of aid for which these applicants qualify can therefore be considered as locally randomly assigned. Under the additional assumption that, in the absence of treatment, the outcome of interest is a smooth function of parental income, the causal effect of grant eligibility is identified by comparing the average outcome of applicants immediately below the income thresholds (treatment group) with that of applicants immediately above (control group).

Let $T_{i, k}$ denote a dummy variable which takes the value one if applicant $i$ is eligible for a grant of level $k(0 \leqslant k \leqslant 6)$. For expositional simplicity and without loss of generality, we define eligibility for a level $k$ grant as eligibility for all level of grants up to $k$, i.e., $T_{i, k}=1 \Rightarrow T_{i, k^{\prime}}=1 \forall k^{\prime}<k$.

Eligibility for a level $k$ grant is a function of the applicant's parental income $z_{i}$ and FNA score $s_{i}$ : 


$$
T_{i, k}=\mathbb{1}\left\{z_{i} \leqslant \bar{z}_{k}\left(s_{i}\right)\right\}
$$

where $\mathbb{1}\{$.$\} is the indicator function and \bar{z}_{k}\left(s_{i}\right)$ is a deterministic function that returns the income eligibility threshold for a level $k$ grant when the applicant's score is $s_{i}$.

The amount of conditional aid $A_{i}$ awarded to applicant $i$ can be defined as the sum of the allowance increments $a_{k}$ for which the applicant qualifies over all possible levels of grant:

$$
A_{i}=\sum_{k=0}^{6} a_{k} T_{i, k}
$$

We model the relationship between grant eligibility and the outcomes of interest using the following reduced-form equation:

$$
y_{i}=\alpha+\sum_{k=0}^{6} \beta_{k} T_{i, k}+\epsilon_{i}
$$

In equation (4), the parameters $\beta_{k}$ are the treatment effects of switching the applicant's eligibility status from a level $k-1$ grant to a level $k$ grant:

$$
\beta_{k}=E\left(y_{i} \mid T_{i, k}=1\right)-E\left(y_{i} \mid T_{i, k-1}=1\right)
$$

Under the assumption that the conditional mean function $E(\epsilon \mid z, s)$ is continuous in parental income $z$ at the income eligibility threshold $\bar{z}_{k}(s)$, the treatment effect $\beta_{k}$ will be identified by the difference:

$$
\lim _{s \uparrow \bar{z}_{k}(s)} E(y \mid z, s)-\lim _{s \downarrow \bar{z}_{k}(s)} E(y \mid z, s)
$$

A specific feature of the BCS grant eligibility formula is that it generates a large number of discontinuity points, which vary with the FNA score and the level of grant considered. As can be seen in figure 1, there are in total 126 different income eligibility thresholds ( 7 grant level thresholds for each of the 18 possible values taken by the FNA score). Due to sample size limitations, separate estimations at each income threshold would yield very imprecise estimates. We choose instead to pool the eligibility thresholds to construct three 
distinct treatment samples. Our estimates are therefore not limited to applicants in the neighborhood of a single discontinuity but are applicable to a more general population.

(i) The first sample (referred to as the "L0/No grant cutoffs") pools the 18 income thresholds that determine eligibility to a level 0 grant as opposed to no grant at all. At these thresholds, we identify the treatment effect $\beta_{0}$ of being eligible for fee waivers on the outcomes of applicants.

(ii) The second sample ("L1/L0 cutoffs") pools the 18 income thresholds between level 1 and level 0 grants. At these thresholds, we identify the treatment effect $\beta_{1}$ of being eligible for an annual cash allowance of 1,500 euros, for applicants who already qualify for the fee waivers.

(iii) Our third treatment sample ("L6/L5 to L2/L1 cutoffs") pools the 90 income thresholds between consecutive levels of grant ranging from level 2 to level 6. At these thresholds, the treatment effect is a weighted average of the treatment effects $\beta_{2}$ to $\beta_{6}$, i.e., the effect of being eligible for an incremental annual allowance of approximately 600 euros, with weights equal to the fraction of applicants around each threshold.

Alternative estimation methods have been proposed to implement equation (6). In this study, we apply both a parametric approach based on a split polynomial approximation (Lee, 2008) and a non-parametric approach based on local linear regression (Lee and Lemieux, 2010).

The split polynomial approximation uses all available observations at a given threshold $\bar{z}$ and chooses a flexible polynomial specification to fit the relationship between the outcome $y_{i}$ and the forcing variable $z_{i}$ (parental income) on either side of the cutoff. The treatment effect is estimated as the discontinuity at the cutoff. Specifically, we estimate the following model using OLS:

$$
y_{i}=\alpha+\beta \cdot T_{i}+\sum_{s=1}^{p} \delta_{s} \cdot\left(z_{i}^{*}\right)^{s}+T_{i} \sum_{s=1}^{p} \gamma_{s} \cdot\left(z_{i}^{*}\right)^{s}+\epsilon_{i}
$$

where $T_{i}$ is a treatment dummy equal to one if $z_{i} \leqslant \bar{z}, p$ is the order of the polynomial function and $z_{i}^{*}=\left(z_{i}-\bar{z}\right) / \bar{z}$ is the relative distance between the 
applicant's parental income and the eligibility threshold $\bar{z}$. The parameter of interest $\beta$ measures the jump between the two regression lines at the threshold $\bar{z}$. In our empirical specifications, we use third-order polynomials for the full samples and second-order polynomials when we consider subsamples. ${ }^{21}$ Our sensitivity analysis shows that our baseline results are robust to varying the order of the polynomial function.

A possible concern with the approach described above is that it may be sensitive to outcome values for observations far away from the cutoffs (Imbens and Lemieux, 2008). The second method avoids this problem by fitting linear regression functions to the observations distributed within a bandwidth $h$ on either side of the income thresholds. We restrict the sample to applicants whose parental income $z_{i}^{*}$ (relative to the cutoff) is in the interval $[-h,+h]$ and estimate the following model using OLS:

$$
y_{i}=\alpha+\beta \cdot T_{i}+\delta . z_{i}^{*}+\gamma \cdot T_{i} \cdot z_{i}^{*}+\epsilon_{i}
$$

where observations are weighted according to a triangular (edge) kernel. We select the optimal bandwidth $h^{*}$ for each regression using the method proposed by Imbens and Kalyanaraman (2012). To assess the sensitivity of our main estimates to the choice of $h^{*}$, we report in the robustness checks section the results obtained with bandwidths set to half and twice the size of the optimal bandwidth.

\section{Results}

In this section, we assess the internal validity of the regression discontinuity design in the context of our study before discussing the reduced-form effets of

\footnotetext{
${ }^{21}$ The samples used in the estimations are restricted to be symmetric around each cutoff and we selected the size of the relative income-distance to cutoff window to ensure that observations located on either side of each cutoff do not cross the previous and next income thresholds for a given FNA score. We further restricted the income intervals around the pooled L6/L5 to L2/L1 cutoffs to be non-overlapping, in order to avoid using the same observation on both sides of the cutoffs.
} 
BCS grant eligibility on college enrollment, persistence and degree completion.

\subsection{Validity of the Research Design}

A key condition for an RD design to produce unbiased estimates of the treatment under consideration is that there is no systematic manipulation of the forcing variable around the cutoffs. In section 2.2.2, we argued that the grant application process minimizes the scope for manipulation of the parental income and FNA score, as the updated income thresholds are not known to applicants when they file their application. In this section, we formally test for the absence of manipulation of the forcing variables by showing that the distribution of parental income does not exhibit discontinuities at the eligibility thresholds and that the observable characteristics of applicants are balanced at the cutoffs.

To check for the absence of manipulation of the forcing variables, we start by examining whether the density of parental income is continuous at the eligibility cutoffs using the test developed by McCrary (2008). This test, which is performed for each treatment sample separately, consists of running kernel local linear regressions of the log of the density separately on both sides of the thresholds. The graphical evidence (Figure 3) suggests that although the number of applicants tends to decrease with parental income around the L1/L0 and the L0/No grant cutoffs, the density of parental income is continuous. This is confirmed in Table 2, which shows that regardless of the treatment sample and year considered, the McCrary test statistic fails to reject the null hypothesis that the log difference in height around the discontinuity points is equal to zero. These result suggest that the probability of submitting an application does not change discontinuously at the income thresholds and that applicants immediately above the cutoffs are unable to manipulate their FNA score or parental income to qualify for a higher level of financial aid.

An alternative approach for testing the internal validity of the RD design is 
to check whether the observable characteristics of applicants are "locally" balanced on either side of the cutoffs. If there was non-random sorting, we could expect some of these characteristics to differ systematically between applicants immediately above and immediately below a given income threshold. For this purpose, we use the information available on the characteristics of applicants, which includes their gender, age, Baccalauréat percentile rank, parental income, FNA score, number of pre-registration choices, whether they applied for accommodation in a subsidized university residence hall and whether their housing application was successful. ${ }^{22}$ We further test for the potential manipulation of parental income and FNA score in current applications by using the information that returning applicants (i.e., 2009 or 2010 applicants who filed an application in 2008 and 2009, respectively) provided in their previous application.

The balance tests are performed by replacing the dependent variable in equations (7) and (8) with each of the observed covariates. Separate parametric and non-parametric $\mathrm{RD}$ estimates are reported for the three treatments in table 3 (covariates of the current year) and table 4 (covariates of the previous year). The results indicate that the observable characteristics of applicants are well balanced on both sides of the cutoffs, since less than 10 percent of the coefficients are significant at the 10 percent level. Furthermore, a chi-squared test based on a system of seemingly unrelated regression with as many equations as baseline covariates cannot reject the null hypothesis that the discontinuity gaps are jointly equal to zero (see the bottom line in each table). Interestingly, the parental income and FNA score that were recorded in the previous application of returning 2009 and 2010 applicants show no significant jumps at the current

\footnotetext{
${ }^{22}$ Note that contrary to grant eligibility, the allocation of university accommodation is not determined by reference to income thresholds. If the demand for a particular hall of residence exceeds the number of available rooms, students are ranked by order of priority based on a "social index" which is computed as the ratio between their parental income and their FNA score plus one. The admission cutoffs therefore vary from one hall of residence to another and there is no reason to expect the probability of being offered student accommodation to change discontinuously at the income thresholds between the different levels of grant. The results of the balancing tests confirm this analysis.
} 
year thresholds. This finding is consistent with the assumption that there is no manipulative sorting around the income cutoffs. ${ }^{23}$

The empirical evidence discussed so far supports the internal validity of the regression discontinuity design to evaluate the impact of BCS grants on applicants' outcomes. The next sections present our main results.

\subsubsection{Discontinuities in the Amount of Conditional Grant Awarded}

For our identification strategy to yield causal estimates of the impact of grant eligibility on student outcomes, it is important to establish that the amount of conditional grant awarded to applicants changes discontinuously at the eligibility thresholds. For this purpose, we compare the differential amount of conditional grant awarded by the student service agency to applicants on either side of the cutoffs with the predicted discontinuities that would result from a strict application of the grant eligibility formula.

Figure 4 plots, for the different treatment samples, the fraction of applicants who were awarded a conditional grant (left panels) and the average amount of cash allowance awarded (right panels) against their relative income-distance to the thresholds. The graphs in the left panels show that approximately 90 percent of theoretically eligible applicants were awarded a conditional grant. The remaining 10 percent are either applications that were withdrawn or applications that were disqualified by the student service agency due to non-compliance with the minimum academic requirements or because of missing supporting documents. ${ }^{24}$ The graphs in the right panels show that the average amount of cash allowance awarded to applicants exhibits sharp discontinuities at the income eligibility thresholds and that these discontinuities are of the expected

\footnotetext{
${ }^{23}$ Suppose that some applicants are able to falsify their parents' tax notice to fall below a given income threshold. In this scenario, incomes below current eligibility thresholds would be more likely to be undervalued than incomes above. We would therefore expect the previously declared income to be higher on average for returning applicants below the current income thresholds than for applicants above.

${ }^{24}$ Note that the data do not allow us to discriminate between the possible reasons for why these applications were turned down by the student service agency (see footnote 16).
} 
magnitude. Importantly, the graphical evidence is not indicative of any systematic breaching of the assessment formula for applicants marginally above the thresholds.

The corresponding parametric and non-parametric RD estimates are reported in Table 5 for each treatment sample, together with the mean value of the dependent variable above the cutoffs. The estimates are almost invariant across specifications and confirm that the discontinuities in the actual amount of conditional grant awarded to applicants are very close to the predicted ones, i.e. 1,350 euros vs. 1,490 euros (L1/L0 cutoffs), 540 vs. 610 euros (L6/L5 to L2/L1 cutoffs) and amounts close to zero on both sides of the L0/No grant cutoffs. ${ }^{25}$ We now examine how these differences affect college enrollment, persistence and degree completion rates.

\subsubsection{Impact on College Enrollment}

To what extent does the eligibility to a need-based grant affect applicants' decision to enroll or to re-enroll in college? To answer this question, we first consider the full sample of applicants, irrespective of their level of study. This sample thus includes college entrants and applicants already enrolled in higher education.

Figure 5 plots for each treatment sample the college enrollment (or reenrollment) rates of applicants against their relative income-distance to the eligibility thresholds. The solid lines are the fitted values from a third-order split polynomial approximation. Although the enrollment rates of applicants appear relatively similar across the different samples (between 75 and 80 percent), the three treatments considered have strikingly different effects on applicants' enrollment decisions. Enrollment rates are unaffected by fee waivers (graph 5a) but exhibit a clear jump when students become eligible for an an-

\footnotetext{
${ }^{25}$ Most of the observed discrepancy between the actual and predicted differences in the average amount of allowance awarded is driven by the fact that approximately 10 percent of applications were turned down by the student service agency for the reasons mentioned above.
} 
nual cash allowance of 1,500 euros (graph 5b). The impact on enrollment rates of subsequent 600 euros increments in the amount of financial aid (graph 5c) is slightly positive but of smaller magnitude.

The RD estimates reported in Table 6 confirm the graphical evidence. They show that applicants' enrollment decisions are affected by the cash allowance component of the need-based grants but not by the fee waiver component. The baseline estimates (Panel A of table 6) are remarkably stable across specifications and suggest that fee waiver eligibility has no significant impact on college enrollment (columns 2 and 3), which is not entirely surprising given the small amounts involved. In contrast, being eligible for a cash allowance of 1,500 euros increases applicants' enrollment rate by 2.7 to 2.8 percentage points (columns 5 and 6 ), the estimates being significant at the 1 percent level. Subsequent 600 euros increments in the amount of cash allowance for higher levels of grants are estimated to have a small positive impact on enrollment rates of approximately 0.7 percentage point, but the effect is only significant at the 10 percent level (columns 8 and 9) in the non-parametric specification.

We investigate the sensitivity of our results to the choice of the polynomial order in the parametric model and to the choice of the bandwidth in the nonparametric model. We find that using a quadratic or a quartic polynomial function instead of a cubic to control for the distance to the income thresholds in the parametric specification does not affect the results (columns 2, 5 and 8 in panel $\mathrm{B}$ of Table 6 ). We further show that changing the bandwidth size to half or twice the value of the optimal bandwidth ${ }^{26}$ in the non-parametric specification yields results that are very similar to those obtained using the Imbens and Kalyanaraman (2012) bandwidth selection algorithm.

To test for jumps at non-discontinuity points, we run a series of placebo regressions in which the income thresholds are artificially set at the midpoints between the true eligibility thresholds (panel $\mathrm{C}$ of table 6 ). Since these mid-

\footnotetext{
${ }^{26}$ If the value of twice the optimal bandwidth exceeds the maximum allowable bandwidth (which was set to avoid including adjacent income cutoffs), we use the maximum bandwidth instead.
} 
points do not correspond to any change in applicants' grant eligibility status, we should expect to find no significant jumps in enrollment rates at the placebo thresholds. The points estimates are indeed close to zero and non-significant in all specifications.

Our final robustness check addresses the possibility that our estimates could not fully capture the impact of grant eligibility on higher education enrollment decisions. In the absence of information on students enrolled in selective higher education institutions in 2008 and 2009, we restricted our sample to applicants who only listed university degree programs among their pre-registration choices. The purpose of this restriction was to minimize the risk of misclassifying applicants who do not appear in the SISE data as not being enrolled in higher education. This type of misclassification would represent a threat to our estimation strategy if a non-negligible share of applicants in our samples ended up enrolling in selective institutions and changed their behavior at the eligibility thresholds. The availability of supplementary data on the universe of undergraduate students enrolled in selective higher education institutions for the academic year 2010-2011 allows us to address this issue for prospective undergraduate students who applied for a grant in 2010. The bottom panel of table 6 shows that the fraction of undergraduate applicants who only listed university degree programs among their pre-registration choices but ended up being enrolled in other higher education institutions is very small (less than 1 percent). Moreover, the regression results show no evidence of significant discontinuities in the probability of attending such institutions at the various income eligibility thresholds. We are therefore confident that our baseline estimates capture the full impact of grant eligibility on applicants' enrollment in higher education.

To investigate potential heterogeneity in the college enrollment effects of need-based grants, we run separate regressions for different subgroups of applicants, based on the year in which they applied, their gender, their level of studies and their academic ability. The results from this heterogeneity analy- 
sis are reported in Table 7. The enrollment effects of the three treatments of interest appear relatively stable across the different years of data (Panel B), which indicates that our results are not driven by a single round of applications. While fee waivers and incremental changes in the amount of allowance are not associated with noticeable discontinuities in the enrollment rates by subgroup, some differences arise when we consider the impact of qualifying for a conditional cash allowance of 1,500 euros. A comparison of the point estimates by gender (Panel C) would suggest that being eligible for such an allowance has a larger enrollment effect for males than for females. The difference, however, is not statistically significant. The subgroup analysis provides clearer evidence that the enrollment effects of level 1 grants are larger for applicants entering undergraduate or graduate degree programs (which correspond to the first and fourth levels of study, respectively) than for continuing students. The estimates reported in Panel D of Table 7 are about twice as large for the first and fourth level of study (4.1 to 4.3 percentage points) as they are for the other levels of study (1.7 to 2.3 percentage points), the difference being significant at the 10 percent level when we consider the non-parametric estimates for undergraduate applicants. These results suggest that the decision to enter university or to pursue graduate studies is more heavily influenced by the provision of financial aid than the decision to proceed to the second or third year of a given degree program.

To investigate whether the impact of grant eligibility on college enrollment varies across levels of academic ability, we divided our samples into four groups based on applicants' percentile rank on the Baccalauréat exam ${ }^{27}$ (Panel E of table 7). Our results indicate that being eligible for a 1,500 euros cash allowance has a positive and significant impact on college enrollment throughout the distribution of academic ability. The point estimates suggest, however, that the enrollment effect of the allowance decreases with ability. Although not

\footnotetext{
${ }^{27}$ To control for the fact that average academic ability tends to rise as we consider applicants who are more advanced in their studies, we computed the quartiles separately for each year of application and level of study.
} 
statistically different, the estimates are twice as large for students in the bottom quartile of the ability distribution (3.4 to 3.6 percentage points) as they are for students in the top quartile (1.7 to 1.8 percentage point). The fact that the cash allowance component of the BCS program seems to have the largest impact on the weakest students raises the question of its effects beyond enrollment. In the next sections, we address this issue by examining the impact of eligibility for a 1,500 euros grant on persistence and degree completion rates. For the sake of brevity, the results for fee waivers and for incremental changes in the amount of allowance are not reported, as we find no evidence of significant discontinuities at these cutoffs. ${ }^{28}$

\subsubsection{Impact on Student Persistence}

To study the impact of financial aid on persistence, we focus on students who applied for a grant to enter an undergraduate or a graduate degree program and follow their progress through college. Our data allow us to track 2008 applicants for up to three years after their application, and 2009 applicants for up to two years.

Figure 6 shows that the college enrollment effect of being eligible for a 1,500 euros allowance is not short-lived, since differences in initial enrollment rates at the L1/L0 cutoffs are carried over to the following year. We investigate more precisely the effect of financial aid on persistence in table 8 , by looking separately at undergraduate and graduate applicants, and by focusing on other dimensions of persistence, such as promotion to the next year level and degree completion rates.

The first three columns of the table report the estimated impact of financial aid on persistence for first year undergraduates. For the sample of 2008 and 2009 applicants, eligibility for a 1,500 euros allowance is found to increase initial enrollment rates by 4.7 to 4.9 percentage points (panel A), the effect being significant and of similar magnitude in the following year (first line of panel B).

\footnotetext{
${ }^{28}$ Results are available upon request.
} 
To have a more complete picture of the progress of first-year applicants through college, we analyze wether they proceed to the next year level as opposed to repeating the first year or dropping out of college. Our results suggest that financial aid has a positive and significant 3.2 to 3.7 percentage point impact on the probability of being enrolled as a second-year student after one year (second line of panel B) but the estimated impact of financial aid on the probability of having obtained all first and second year credits after two years of undergraduate studies is not statistically significant (third line of panel B). The enrollment effect of being eligible for a 1,500 euros cash allowance is still detectable for undergraduate students two years after their application, the non-parametric estimate showing a marginally significant 4.4 percentage points enrollment gap in 2010 for prospective undergraduate students who applied for a grant in 2008 (first line of Panel C). However, we find no significant effects of the grant on the probability of being enrolled in the third year level after two years and on the probability of graduating on time (second and third lines of Panel C). Overall, our estimates demonstrate a clear impact of financial aid on student persistence for undergraduate applicants but show no significant effects on on-time degree completion. These results should nevertheless be interpreted with caution, since the lack of statistical significance for the effects after two years could be due to the fact that they are estimated on a relatively small sample (only applicants from the 2008 round of applications can be followed over three years). Moreover, our data do not allow examining degree completion effects beyond a three-year window.

Table 8 shows that the effects of financial aid on persistence are strong for graduate applicants (columns 4 to 6). Students who applied for a grant in 2008 or 2009 to start a graduate degree program are not only more likely to enroll in college if they are eligible for a 1,500 euros cash allowance (first line of Panel A). They are also more likely to successfully complete all their first-year credits (second line of panel A), to proceed to the next year level (first and second lines of panel B) and to graduate on time (fourth line on panel B). 
The estimated effects on enrollment, promotion and graduation are of similar magnitude, between 4 and 5 percentage points. These results suggest that the cash allowance component of the BCS grant program is particularly effective at the graduate level, as it increases not only enrollment and persistence, but also degree graduation rates. The overall degree completion effect is likely to be a mix of the grant's effects on the "marginal" and "inframarginal" students, whose respective contributions cannot be distinguished within our empirical framework. Some of the students who would not have enrolled if they had not been awarded a conditional cash allowance will have completed their degree after joining the master's program. In addition, the grant could allow students who would have attended college irrespective of financial aid to study in better conditions, thus increasing their chances of success.

\subsubsection{Impact on Degree Completion}

Figure 7 and Table 9 extend the analysis by showing the impact of financial aid on students who applied for a grant before entering the final year of a degree program, either the third year of a bachelor's degree or the second year of a master's degree. The pooled estimates indicate (columns 8 and 9) that being eligible for a cash allowance of 1,500 euros not only has a positive and significant 2 percentage point impact on the enrollment rates of final-year applicants but also increases their chances of completing their degree by a similar order of magnitude (about 3 percentage points). The effect are more precisely estimated for the large sample of undergraduate applicants (columns 2 and 3) than for the smaller sample of graduate applicants (columns 5 and 6). The fact that low-income students who progressed to the final year of a degree program are positively selected on achievement appears as a plausible explanation for why the estimated degree completion effects of financial aid tend to be larger for third-year undergraduate or second-year graduate students than for college entrants. 


\section{Conclusion and Discussion}

Using a regression discontinuity design, we provide causal evidence on the effects of a large French need-based grant program on college enrollment, persistence and degree completion for low-income students. Our results show a significant impact of being eligible for a 1,500 euros cash allowance on enrollment decisions, not only at college entry, but also at higher levels of study. We further find evidence of a positive effect of financial aid on persistence in college. Prospective first-year undergraduate applicants who qualify for the cash allowance are not only more likely to start college, but also to re-enroll in the following year and to progress to the next year level, although the effect seems to fade out after two years. At the master's level, the effects of financial aid are found to be more persistent, as graduate applicants who are eligible for a 1,500 euros cash allowance are both more likely to pursue graduate studies and to complete their master's degree after two years. These finding are consistent with the selection process occurring in French universities, where admission is not competitive but where the weakest students tend to drop out early. Our estimates suggest that the academic prospects of first-year undergraduates who start college as a result of being awarded a grant are similar to those of other college entrants, many of whom drop out along the way. But as students progress through college, only the more able remain, and grants appear particularly effective in subsidizing low-income students who have reached these higher levels of study. Consistent with this interpretation, we also find positive effects on degree completion for prospective final year undergraduate and graduate students.

Simple back-of-the-envelope calculations can be performed to get some sense of the program's cost-effectiveness. Our estimates show that the provision of 1,500 euros cash allowances to prospective undergraduate or graduate students increases their college enrollment rates by approximately 4.5 percentage points from a baseline rate of 73 percent. The cost of inducing more students to 
enroll in higher education through the provision of such grants includes the distribution of cash allowances to all eligible students, the financing of two years of college education for students who are induced to enroll as a result of the grant, and the earnings foregone by these students while attending college. According to our computations, these costs would amount to approximately 105,000 euros per undergraduate student induced to attend college for two years (without graduating), and 115,000 euros per graduate student induced to complete a master's degree. ${ }^{29}$ These costs are to be compared with the benefits from college studies. In France, the annual differential in gross wages plus taxes between high school graduates and individuals with some college but no bachelor's degree is around 13 percent. This relatively modest return to some college could be partly driven by the small signaling value of the college admission process in France. The corresponding wage differential between individuals holding a bachelor's degree and individuals holding a master's degree is much higher, around 35 percent. Given these substantial returns to a graduate degree, we estimate the net present discounted value of distributing cash allowances of 1,500 euros per student induced to attend college to be much larger for graduate applicants (310,000 euros) than for undergraduate applicants (40,000 euros). It would take approximately 15 years to balance the costs and benefits of such grants for graduate applicants, as opposed to 30 years for undergraduates.

While these calculations suggest that the BCS grant program is cost-effective for both college entrants and continuing students, they point out to larger net social benefits at the graduate level. Improving the effectiveness of need-based grant programs therefore requires identifying adequate policy responses to the non-financial barriers - such as poor academic preparation and insufficient monitoring - that could affect the ability of low-income college entrants to persist to degree completion.

\footnotetext{
${ }^{29}$ See the online appendix for the details of the cost-benefit calculations.
} 


\section{References}

Abraham, K. and Clark, M. (2006). "Financial Aid and Students' College Decisions: Evidence from the District of Columbia Tuition Assistance Program". Journal of Human Resources, pp. 578-610.

Angrist, J. (1993). "The Effect of Veterans Benefits on Education and Earnings". Industrial and Labor Relations Review, 46(4), pp. 637-652.

Angrist, J., Lang, D., and Oreopoulos, P. (2009). "Incentives And Services for College Achievement: Evidence from a Randomized Trial". American Economic Journal: Applied Economics, 1(1), pp. 139-163.

Beffy, M., Fougère, D., and Maurel, A. (2013). "The Effect of College Employment on Graduation: Evidence From France". CEPR working paper 9565.

Bettinger, E. P. (2004). "How Financial Aid Affects Persistence". In Hoxby, C. M., editor, College Choices: The Economics of Where to Go, When to Go, and How to Pay For It. University of Chicago Press.

Bettinger, E. P., Long, B. T., Oreopoulos, P., and Sanbonmatsu, L. (2012). "The Role of Application Assistance and Information in College Decisions: Results from the H\&R Block FAFSA Experiment'. Quarterly Journal of Economics, 127(3), pp. 1205-1242.

Bound, J. and Turner, S. (2002). "Going to War and Going to College: Did World War II and the G.I. Bill Increase Educational Attainment for Returning Veterans?". Journal of Labor Economics, 20(4), pp. 784-815.

Bound, J. and Turner, S. (2003). "Closing the Gap or Widening the Divide: The Effects of the G.I. Bill and World War II on the Educational Outcomes of Black Americans". Journal of Economic History, 63(1), pp. 145-177.

Brodaty, T., Gary-Bobo, R., and Prieto, A. (2012). "Do Risk Aversion and Wages Explain Educational Choices?". Working Paper.

Castleman, B. L. and Long, B. T. (2012). "Looking Beyond College Enrollment: The Causal Effect of Need-Based Grants on College Access, Persistence and Graduation". Working Paper. 
Cornwell, C., Mustard, D., and Sridhar, D. (2006). "The Enrollment Effects of Merit-Based Financial Aid: Evidence from Georgia's HOPE Scholarship". Journal of Labor Economics, 24(4), pp. 761-786.

Deming, D. and Dynarski, S. (2010). "College Aid". In Levine, P. B. and Zimmerman, D. J., editors, Targeting Investments in Children: Fighting Poverty When Resources are Limited, chapter 10. University of Chicago Press.

Dynarski, S. (2000). "Hope for Whom? Financial Aid for the Middle Class and its Impact on College Attendance". National Tax Journal, 53(3), pp. 629 661.

Dynarski, S. (2003). "Does Aid Matter? Measuring the Effect of Student Aid on College Attendance and Completion". American Economic Review, 93(1), pp. 279-288.

Dynarski, S. (2008). "Building the Stock of College Educated Labor". Journal of Human Resources, 43(3), pp. 576-610.

Dynarski, S. and Scott Clayton, J. (2008). "Complexity and Targeting in Federal Student Aid: A Quantitative Analysis". Tax Policy and The Economy, 22, pp. 109-150.

Dynarski, S. and Wiederspan, M. (2012). "Student Aid Simplification: Looking Back and Looking Ahead'. National Tax Journal, 65(1), pp. 211-234.

Goldin, C. and Cellini, S. R. (2012). "Does Federal Student Aid Raise Tuition? New Evidence on For-Profit Colleges". NBER Working Paper 17827.

Goldrick-Rab, S., Harris, D. N., Kelchen, R., and Benson, J. (2012). "NeedBased Financial Aid and College Persistence: Experimental Evidence from Wisconsin". IRP Discussion Paper 1393-12.

Goodman, J. (2008). "Who Merits Financial Aid? Massachussets' Adams Scholarship". Journal of Public Economics, 92(10-11), pp. 2121-2131.

Imbens, G. and Kalyanaraman, K. (2012). "Optimal Bandwidth Choice for the Regression Discontinuity Estimator". The Review of Economic Studies, 79(3), pp. 933-959. 
Imbens, G. and Lemieux, T. (2008). "Regression Discontinuity Designs: A Guide to Practice". Journal of Econometrics, 142(2), pp. 615-635.

Kane, T. J. (1995). "Rising Public College Tuition and College Entry: How Well Do Public Subsidies Promote Access to College?". NBER Working Paper 5164.

Kane, T. J. (2006). "Public Intervention in Post-Secondary Education". In Hanushek, E. and Welch, F., editors, Handbook of the Economics of Education, volume 2, chapter 23, pp. 1369-1401. Elsevier.

Kane, T. J. (2007). "Evaluating the Impact of the D.C. Tuition Assistance Grant Program". Journal of Human Resources, 43(2), pp. 555-582.

Lee, D. S. (2008). "Randomized Experiments from Non-Random Selection in U.S. House Elections". Journal of Econometrics, 142(2), pp. 675-697.

Lee, D. S. and Lemieux, T. (2010). "Regression Discontinuity Designs in Economics". Journal of Economic Literature, 48(2), pp. 281-355.

McCrary, J. (2008). "Manipulation of the Running Variable in the Regression Discontinuity Design: A Density Test”. Journal of Econometrics, 142(2), pp. 698-714.

MEN (2013). Repères et Références Statistiques sur les Enseignements, la Formation et la Recherche - Édition 2013. Ministère de l'Éducation Nationale.

OECD (2012). Education at a Glance 2012: OECD Indicators. OECD Pub.

OVE (2011). La Vie Étudiante - Repères - Édition 2011. Observatoire de la Vie Étudiante.

Seftor, N. and Turner, S. (2002). "Back to School: Federal Student Aid Policy and Adult College Enrollment". Journal of Human Resources, 37(2), pp. 336-352.

Stanley, M. (2003). "College Education and the Mid-Century G.I. Bills". Quarterly Journal of Economics, 118(2), pp. 671-708.

Turner, L. J. (2012). "The Incidence of Student Financial Aid: Evidence from the Pell Grant Program". Working Paper. 
Figure 1: Income Eligibility Thresholds for the Different Levels of BCS Grant

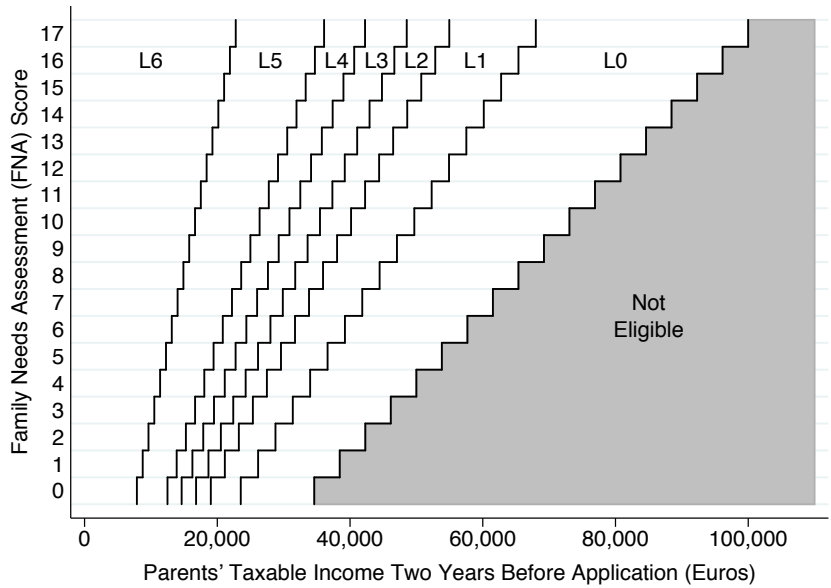

Notes: The figure shows the income eligibility thresholds for the different levels of grants (denoted L0 to L6) awarded through the French Bourses sur critères sociaux program in 2009. The thresholds, which depend on the applicant's family need assessment (FNA) score, apply to parental taxable income earned two years before the application (x-axis). The FNA score (y-axis) is capped at 17 and has a median value of 3. Income thresholds are expressed in 2011 euros.

Figure 2: Amount of Annual Cash Allowance Awarded to Applicants with an FNA Score of 3 Points, as Function of their Parents' Taxable Income

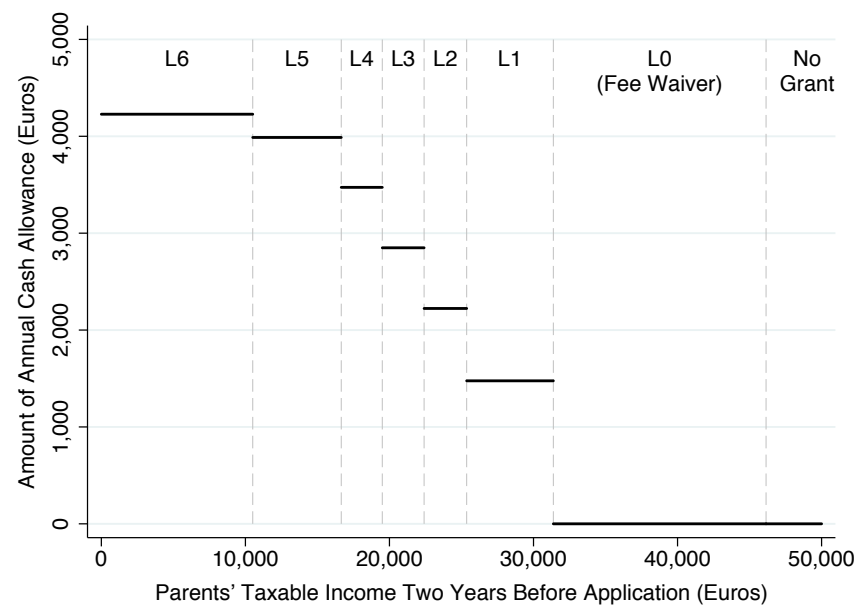

Notes: The figure shows the amount of annual cash allowance awarded in 2009 to BCS grant applicants with a family needs assessment (FNA) score of 3 points (median value), as a function of their parents' taxable income two years before the application. Applicants eligible for a level 0 grant qualify for fee waivers only. Applicants eligible for higher levels of grant qualify for fee waivers and an annual cash allowance, the amount of which varies with the level of grant: 1,476 euros (level 1), 2,223 euros (level 2), 2,849 euros (level 3), 3,473 euros (level 4), 3,988 euros (level 5) and 4,228 euros (level 6). Income thresholds and allowance amounts are expressed in 2011 euros. 
Figure 3: McCrary (2008) Test for Manipulation of the Assignment Variable at Different Income Eligibility Thresholds

(a) Fee Waiver (L0/No Grant Cutoffs)

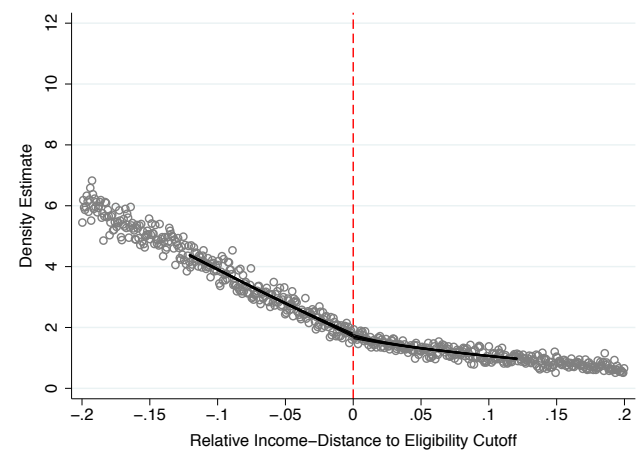

(b) $€ 1,500$ Allowance (L1/L0 Cutoffs)

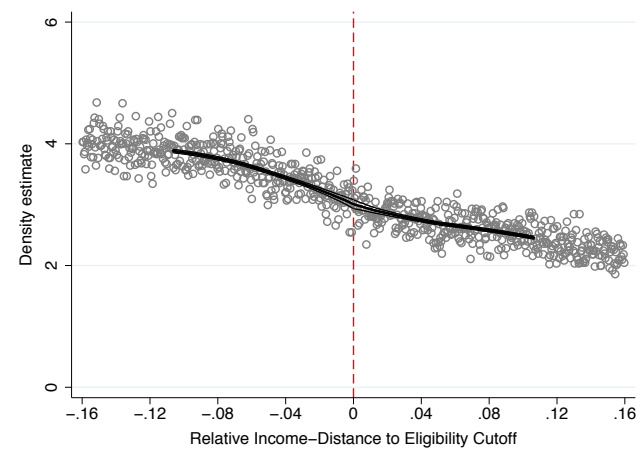

(c) $€ 600$ Increment (L6/L5 to L2/L1 Cutoffs)

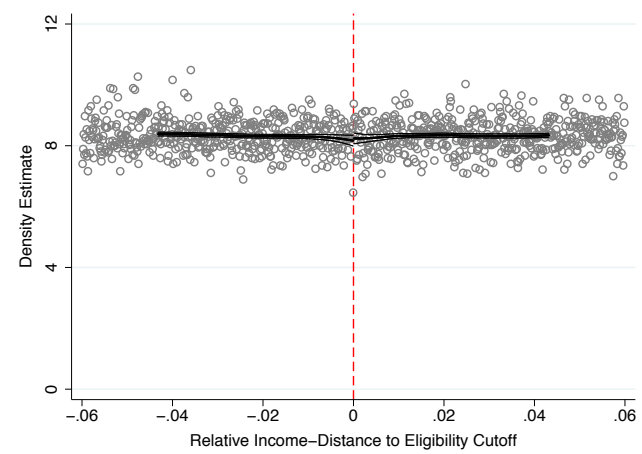

Notes: The figure plots weighted kernel density estimates, performed separately on either side of income eligibility thresholds. The "fee waiver" sample includes applicants whose parental income is close to the eligibility thresholds between no grant and a level 0 grant (fee waiver only). The "1,500 euros allowance" sample includes applicants in the vicinity of the income thresholds between level 0 and level 1 grants, where students (who already qualify for the fee waiver) become eligible for an annual cash allowance of 1,500 euros. The "600 euros increment" sample includes applicants close to the income thresholds between consecutive levels of grant in the level 2 to level 6 range, where the amount of annual cash allowance increases by 600 euros on average. The $\mathrm{x}$-axis is the relative distance between the applicant's parental income and the income eligibility threshold. The optimal bandwidth and bin size are obtained using the selection procedure proposed by McCrary (2008). 
Figure 4: Fraction of Applicants Awarded a Conditional Grant and Average Amount of Allowance Awarded at Different Income Eligibility Thresholds

(a) Fee Waiver (L0/No Grant Cutoffs)

Fraction Awarded a Conditional Grant

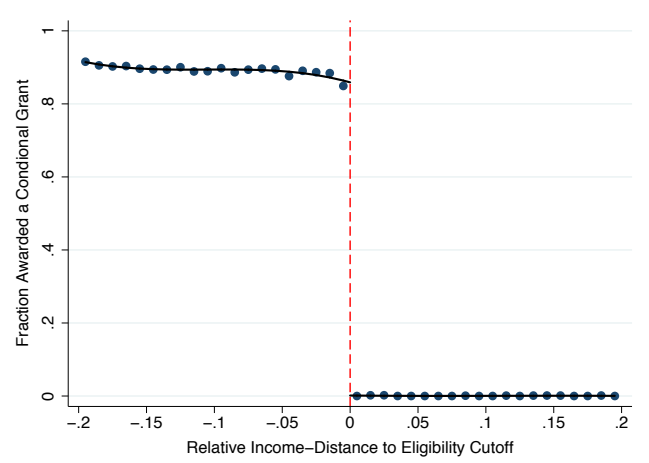

Average Amount of Allowance Awarded

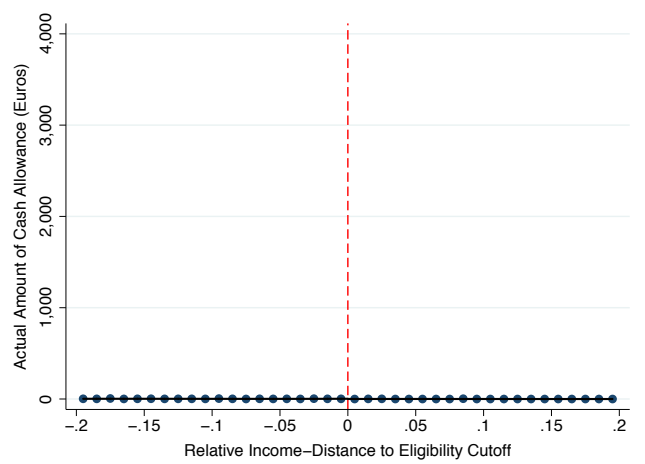

(b) $€ 1,500$ Allowance (L1/L0 Cutoffs)

Fraction Awarded a Conditional Grant

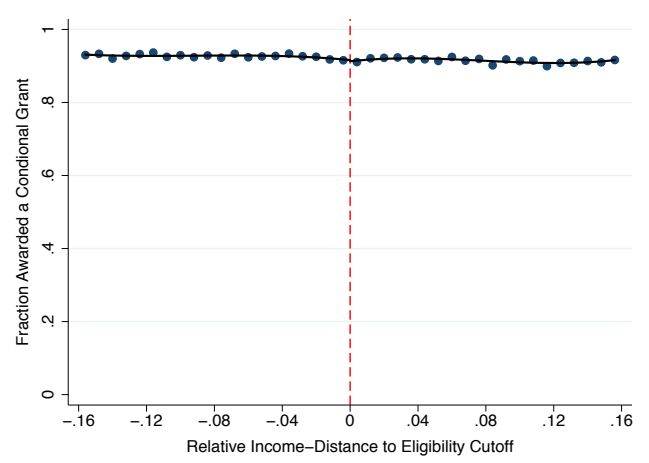

Average Amount of Allowance Awarded

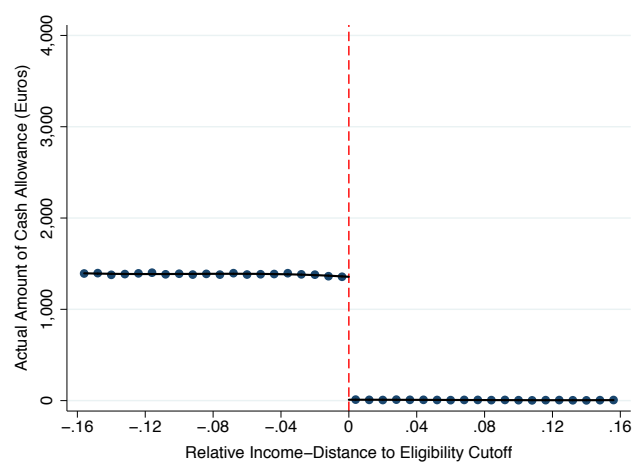

(c) $€ 600$ Increment (L6/L5 to L2/L1 Cutoffs)

Fraction Awarded a Conditional Grant

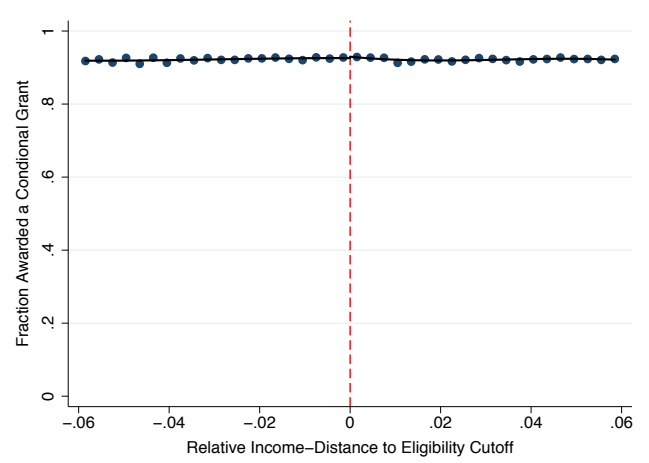

Average Amount of Allowance Awarded

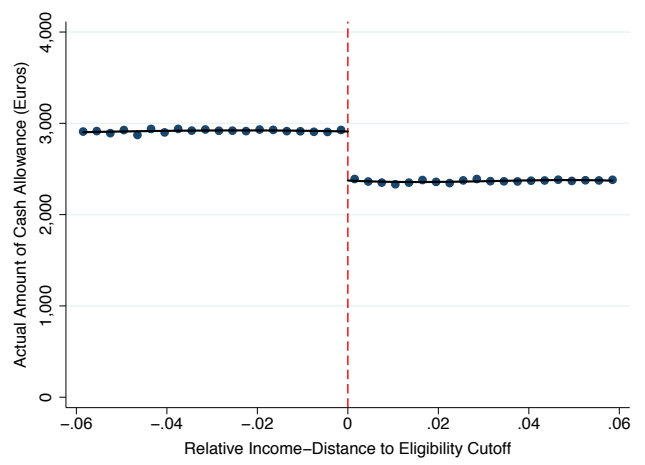

Notes: The circles represent the average fraction of applicants who were awarded a conditional grant (left panels) and the average amount of allowance awarded (right panels) per interval of relative income-distance to the eligibility thresholds. The solid lines are the fitted values from a third-order polynomial approximation which is estimated separately on both sides of the cutoffs. The vertical lines identify the eligibility cutoffs. 
Figure 5: College Enrollment Rate of Grant Applicants at Different Income Eligibility Thresholds

(a) Fee Waiver (L0/No grant Cutoffs)

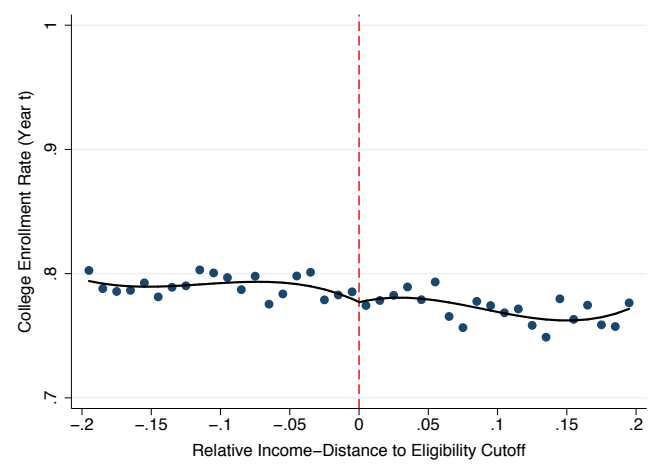

(b) $€ 1,500$ Allowance (L1/L0 Cutoffs)

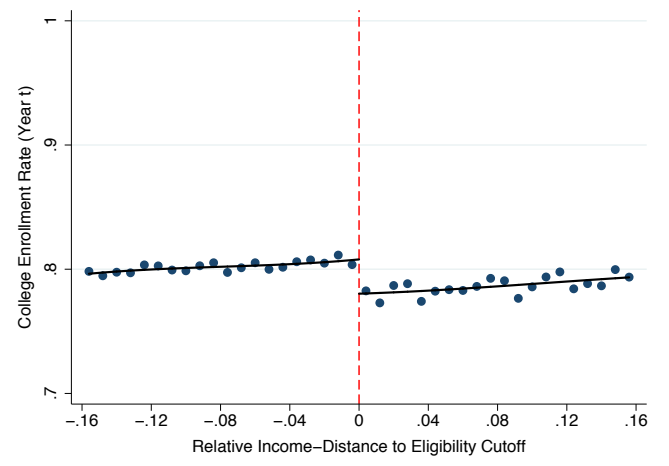

(c) $€ 600$ Increment (L6/L5 to L2/L1 Cutoffs)

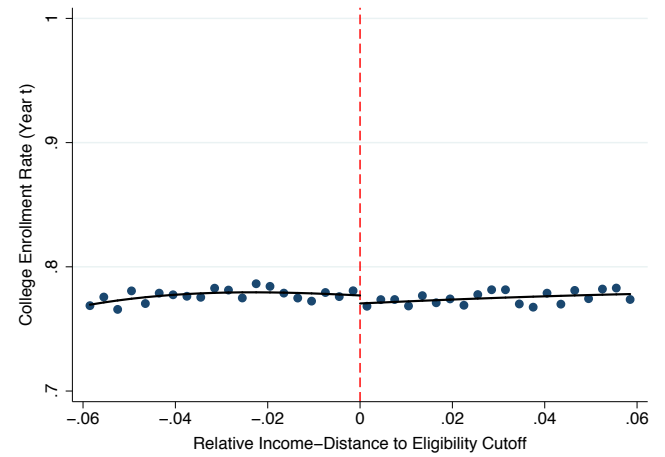

Notes: The circles represent the mean college enrollment rate of grant applicants per interval of relative incomedistance to the eligibility thresholds. The solid lines are the fitted values from a third-order polynomial approximation which is estimated separately on both sides of the cutoffs. The vertical lines identify the eligibility cutoffs. 
Figure 6: College Enrollment and Persistence Rates of First-Year Undergraduate and Graduate Applicants at the 1,500 euros Allowance Eligibility Cutoff

(a) Enrolled in College in Current Year

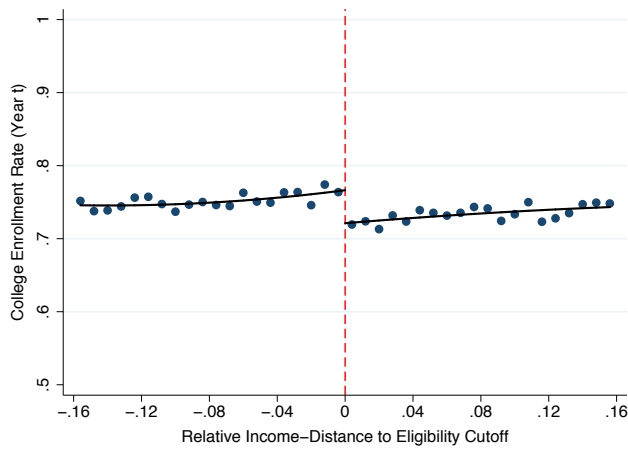

(b) Enrolled in College in Following Year

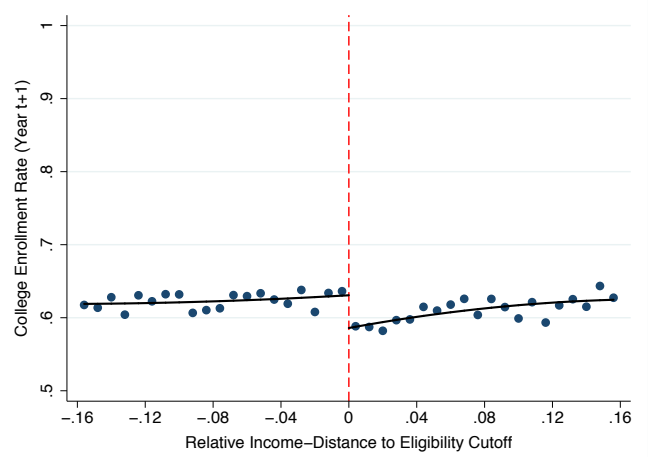

Notes: The circles represent the mean college enrollment rate of first-year undergraduate or graduate applicants in the year of application (left panel) and in the following year (right panel), per interval of relative incomedistance to the eligibility thresholds. The sample includes 2008 and 2009 applicants entering the first year of a three-year bachelor's degree or the first year of a two-year master's degree. The solid lines are the fitted values from a second-order polynomial approximation which is estimated separately on both sides of the cutoff. The vertical lines identify the eligibility cutoffs.

Figure 7: College Enrollment and Degree Completion Rates of Final-Year Undergraduate and Graduate Applicants at the 1,500 euros Allowance Eligibility Cutoff

(a) Enrolled in College in Current Year

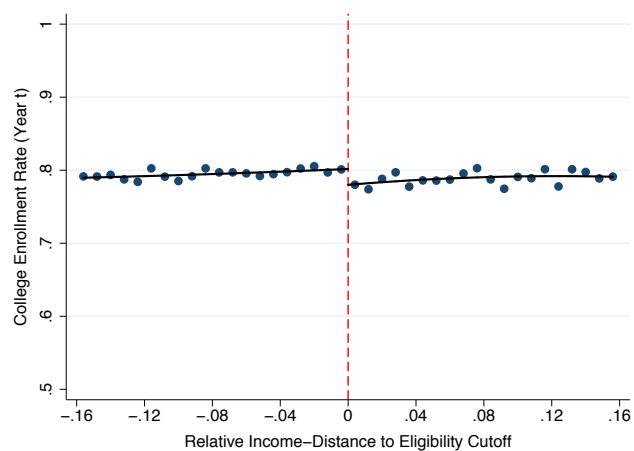

(b) Completed Degree in Current Year

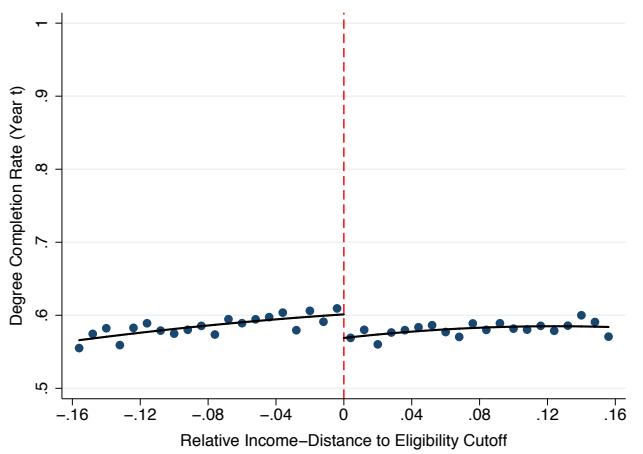

Notes: The circles represent the mean college enrollment (left panel) and the degree completion rate (right panel) of final year undergraduate or graduate applicants, per interval of relative income-distance to the eligibility thresholds. The sample includes 2008 to 2010 applicants entering the final year of a three-year bachelor's degree or the final year of a two-year master's degree. The solid lines are the fitted values from a second-order polynomial approximation which is estimated separately on both sides of the cutoff. The vertical lines identify the eligibility cutoffs. 
Table 1: Descriptive Statistics on Applicants to BCS Need-Based Grants at Different Income Eligibility Thresholds (2008-2010)

\begin{tabular}{|c|c|c|c|}
\hline $\begin{array}{l}\text { Treatment Sample: } \\
\text { (Income Eligibility Thresholds) }\end{array}$ & $\begin{array}{c}\text { Fee Waiver } \\
\text { (L0/No Grant) } \\
(1)\end{array}$ & $\begin{array}{c}€ 1,500 \text { Allowance } \\
(\mathrm{L} 1 / \mathrm{L} 0) \\
(2)\end{array}$ & $\begin{array}{c}\text { €600 Increment } \\
\text { (L6/L5 to L2/L1) } \\
(3)\end{array}$ \\
\hline \multicolumn{4}{|l|}{ Applicants: } \\
\hline Female & .59 & .60 & .61 \\
\hline Age & $\begin{array}{l}20.5 \\
(2.3)\end{array}$ & $\begin{array}{l}20.6 \\
(2.1)\end{array}$ & $\begin{array}{c}20.9 \\
(2.2)\end{array}$ \\
\hline Baccalauréat Percentile Rank & $\begin{array}{r}61.2 \\
(23.6)\end{array}$ & $\begin{array}{r}59.3 \\
(23.6)\end{array}$ & $\begin{array}{r}56.5 \\
(23.8)\end{array}$ \\
\hline Number of pre-Registration Choices & $\begin{array}{r}1.8 \\
(1.1)\end{array}$ & $\begin{array}{r}1.7 \\
(1.0)\end{array}$ & $\begin{array}{r}1.7 \\
(1.0)\end{array}$ \\
\hline \multicolumn{4}{|l|}{ Applications: } \\
\hline Parents' Taxable Income (Euros) & $\begin{array}{r}42,068 \\
(9,066)\end{array}$ & $\begin{array}{r}31,632 \\
(6,815)\end{array}$ & $\begin{array}{r}21,669 \\
(6,469)\end{array}$ \\
\hline Family Needs Assessment Score & $\begin{array}{r}2.9 \\
(2.3)\end{array}$ & $\begin{array}{r}3.4 \\
(2.5)\end{array}$ & $\begin{array}{r}3.8 \\
(2.8)\end{array}$ \\
\hline Number of Siblings & $\begin{array}{l}0.9 \\
(.8)\end{array}$ & $\begin{array}{l}1.0 \\
(.9)\end{array}$ & $\begin{array}{r}1.2 \\
(1.1)\end{array}$ \\
\hline Distance to College (Km) & $\begin{array}{r}137 \\
(229)\end{array}$ & $\begin{array}{r}132 \\
(218)\end{array}$ & $\begin{array}{r}132 \\
(230)\end{array}$ \\
\hline Applied for University Housing & .37 & .31 & .32 \\
\hline Successful Housing Application & .12 & .13 & .16 \\
\hline Level of Study: & & & \\
\hline First Year & .28 & .25 & .25 \\
\hline Second Year & .26 & .28 & .27 \\
\hline Third Year & .22 & .24 & .24 \\
\hline Fourth Year & .14 & .14 & .14 \\
\hline Fifth Year & .11 & .10 & .10 \\
\hline Conditional Grant: & & & \\
\hline Awarded a Conditional Grant & .70 & .92 & .92 \\
\hline Amount of Cash Allowance Awarded (Euros) & $\begin{array}{r}2 \\
(64)\end{array}$ & $\begin{array}{r}819 \\
(746)\end{array}$ & $\begin{array}{r}2,642 \\
(1,114)\end{array}$ \\
\hline Final grant: & & & \\
\hline Receives Grant & .51 & .70 & .70 \\
\hline Amount of Cash Allowance Received (Euros) & $\begin{array}{r}13 \\
(202)\end{array}$ & $\begin{array}{r}658 \\
(759)\end{array}$ & $\begin{array}{r}2,014 \\
(1480)\end{array}$ \\
\hline College Enrollment: & & & \\
\hline Enrolled in College & .79 & .80 & .78 \\
\hline $\mathrm{N}$ & 96,390 & 194,513 & 284,601 \\
\hline
\end{tabular}

Notes: The samples are constructed from the AGLAE administrative dataset, which covers the universe of applicants to need-based grants awarded through the French Bourses sur critères sociaux program for the period 2008 to 2010. Only applicants who listed university degree programs in each of their pre-registration choices, who submitted their application before July and whose FNA score does not vary across pre-registration choices are included. The "fee waiver" treatment sample (column 1) includes applicants whose parental income is within \pm 20 percent of the eligibility thresholds between no grant and a level 0 grant (which consists of a fee waiver). The "1,500 euros allowance" sample (column 2) includes applicants whose parental income is within \pm 16 percent of the income thresholds between level 0 and level 1 grants, where students (who already qualify for the fee waiver) become eligible for an annual cash allowance of 1,500 euros. The "600 euros increment" sample (column 3) includes applicants whose parental income is within \pm 6 percent of the income thresholds between consecutive levels of grant in the level 2 to level 6 range, where the amount of annual cash allowance increases by 600 euros on average. The applicants' percentile rank on the Baccalauréat high school graduation exam was retrieved from the OCEAN dataset covering the period 2003 to 2010. Information on college enrollment comes from the SISE dataset which includes all students registered in a French public university in academic years 2008-2009 through 2010-2011. All amounts are expressed in 2011 euros. Standard deviations are in parentheses. 


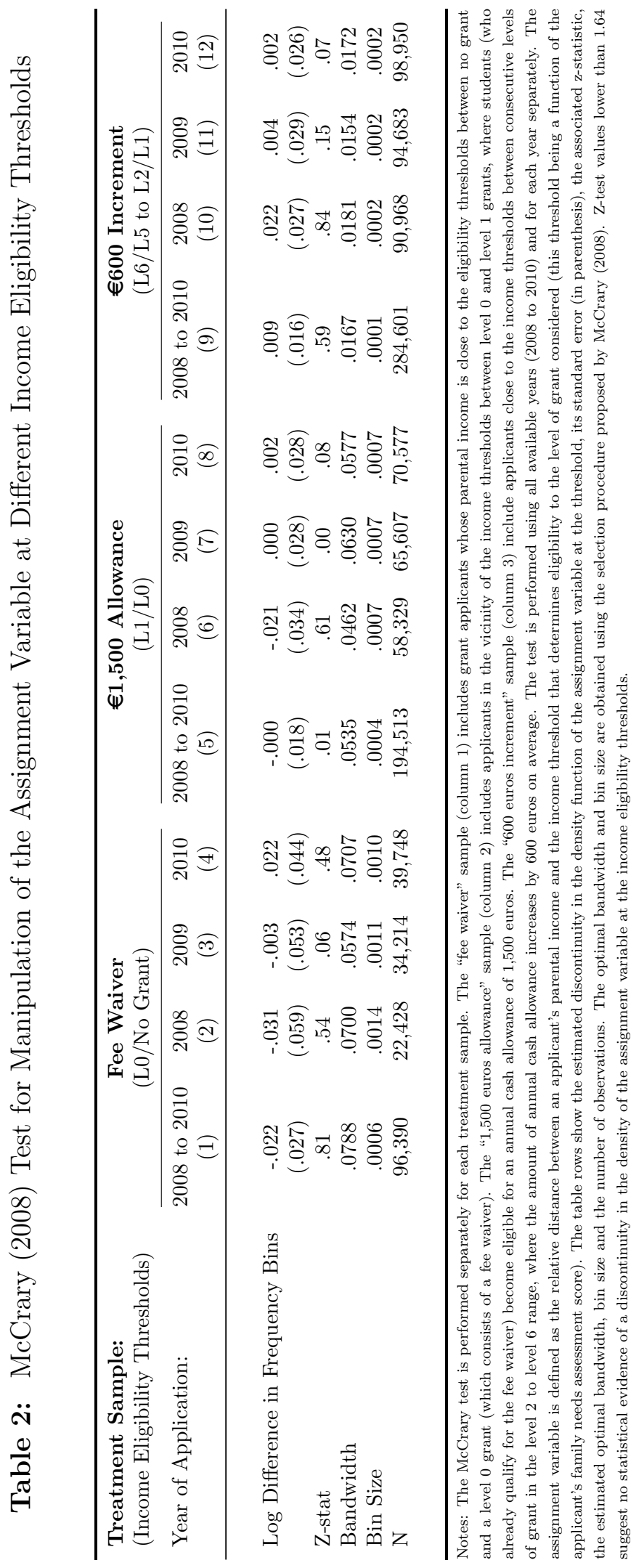




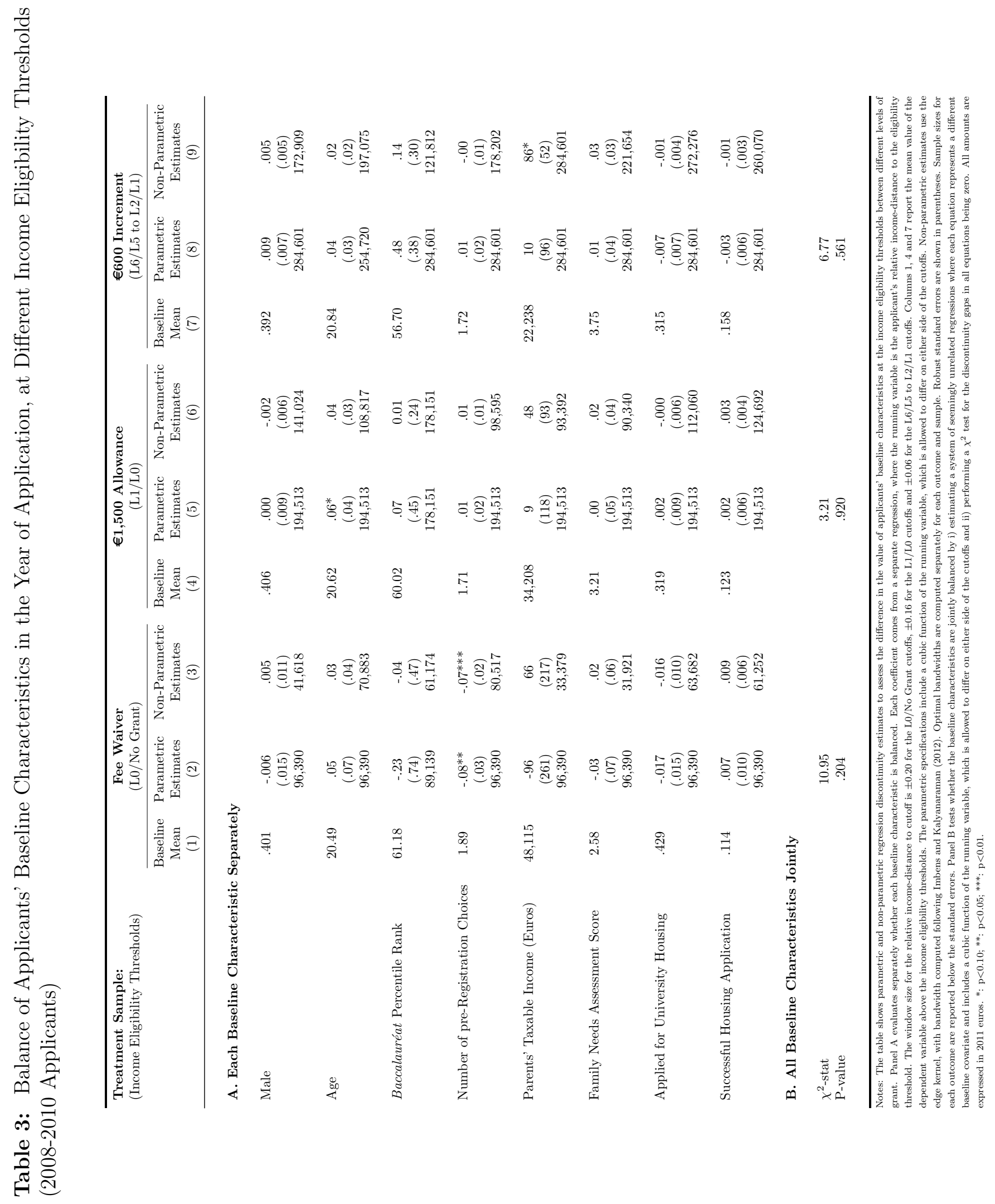




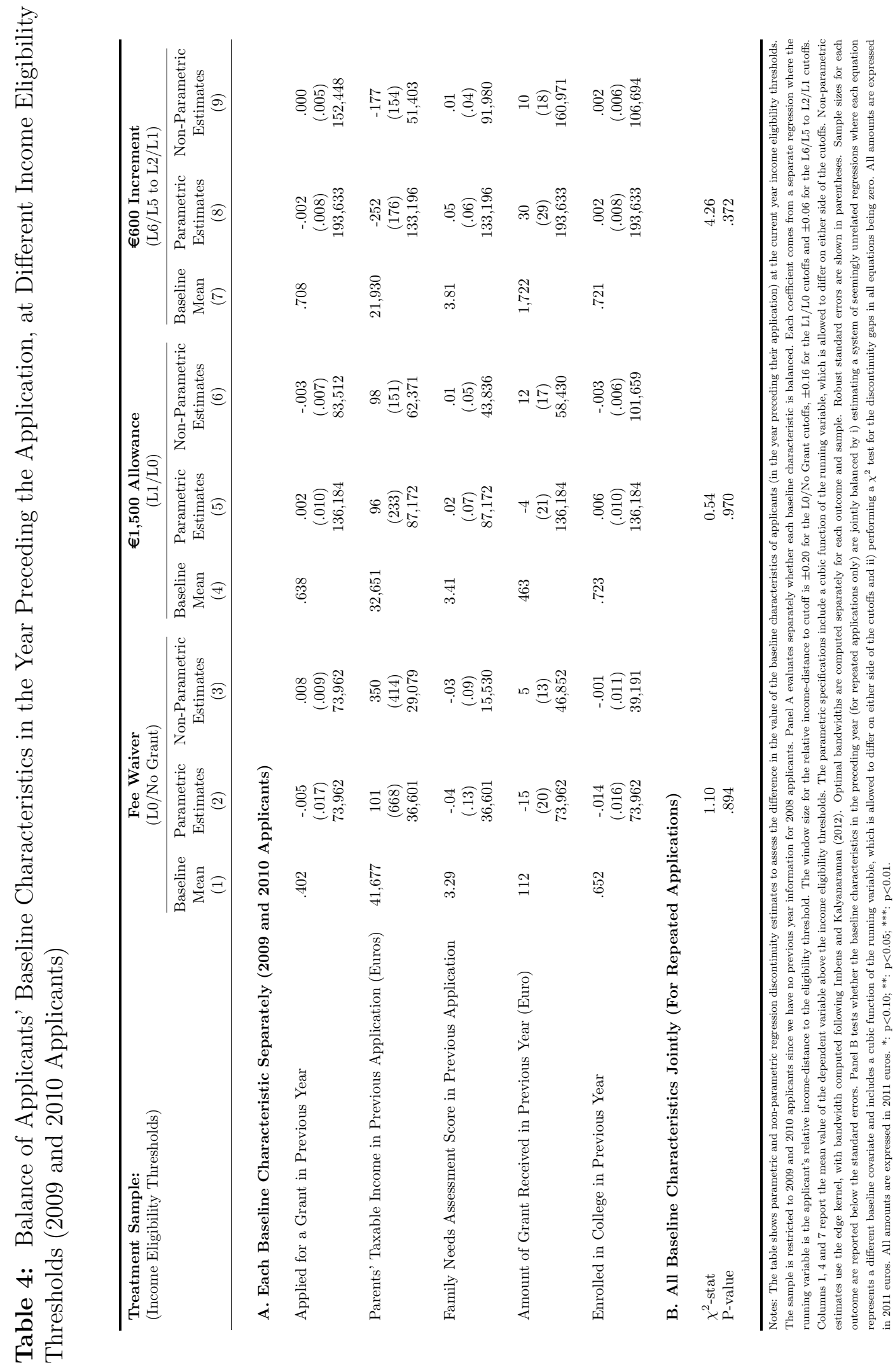




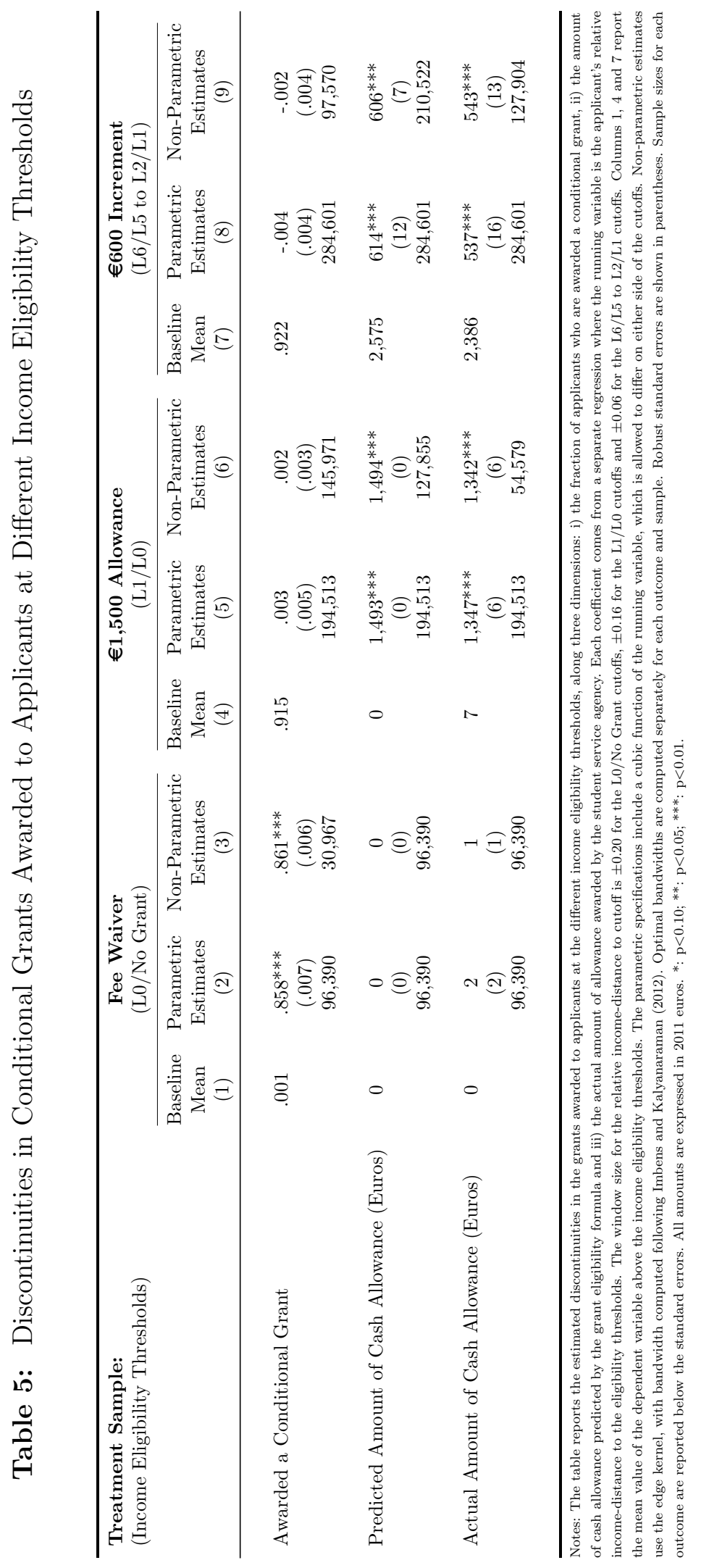




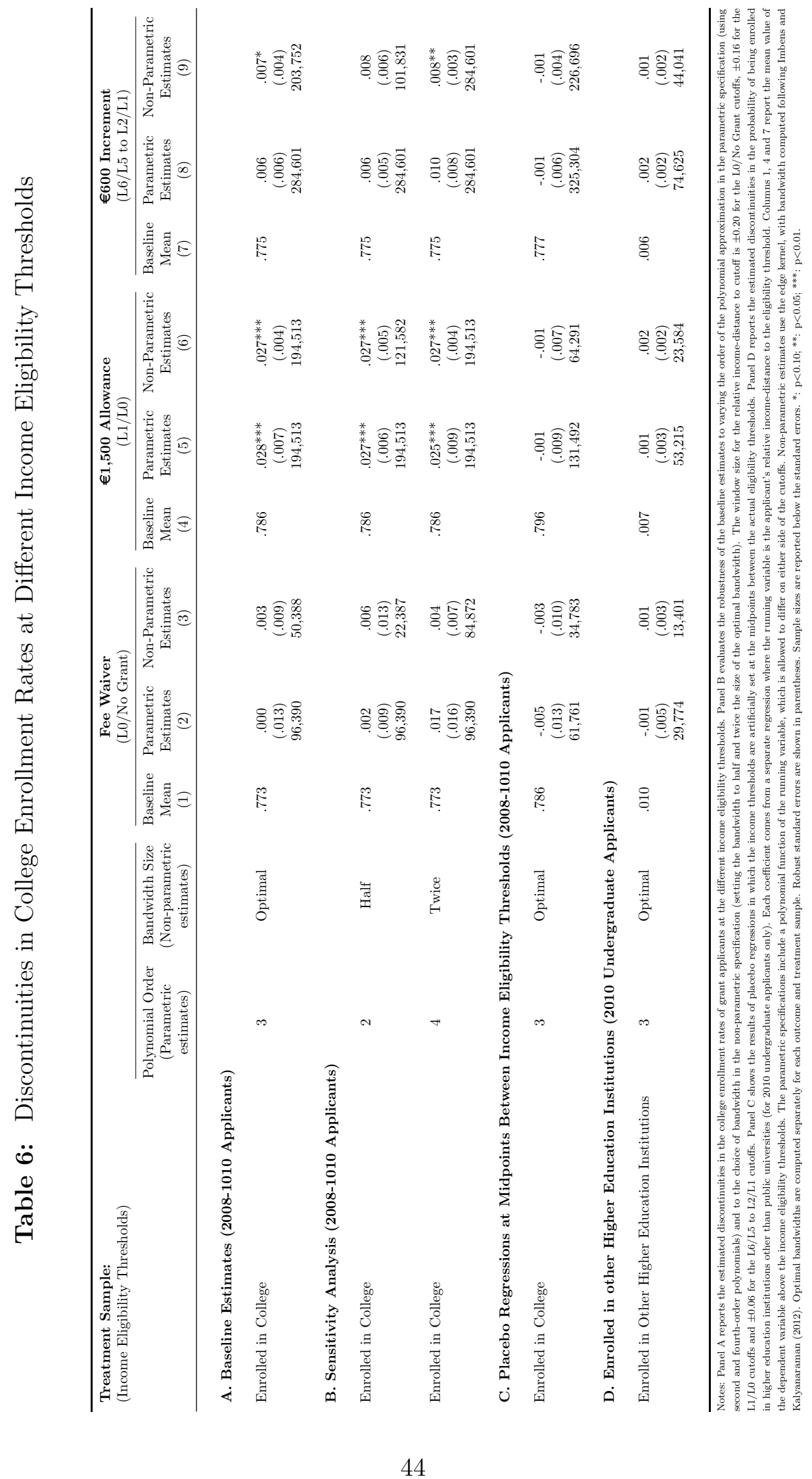




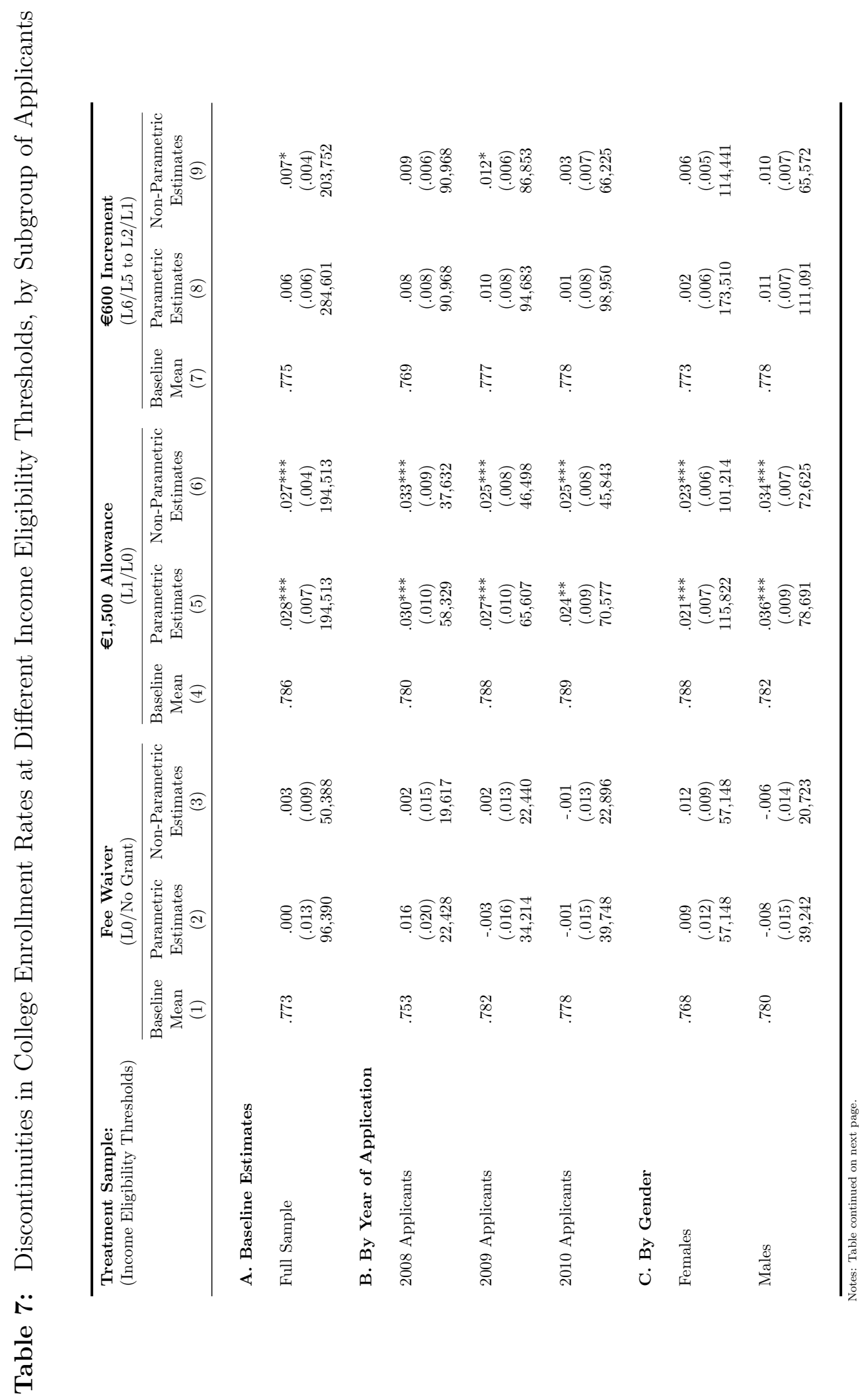




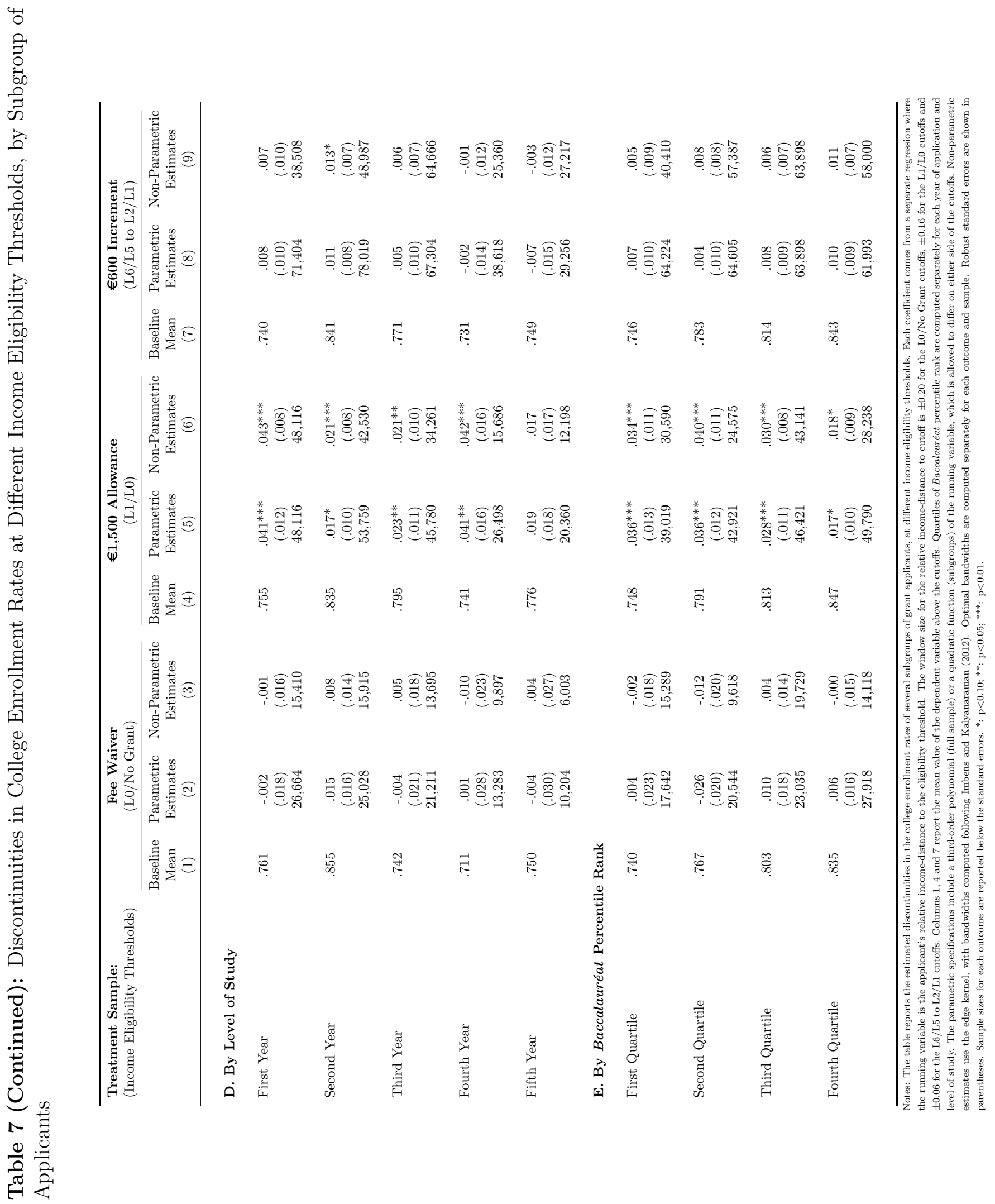




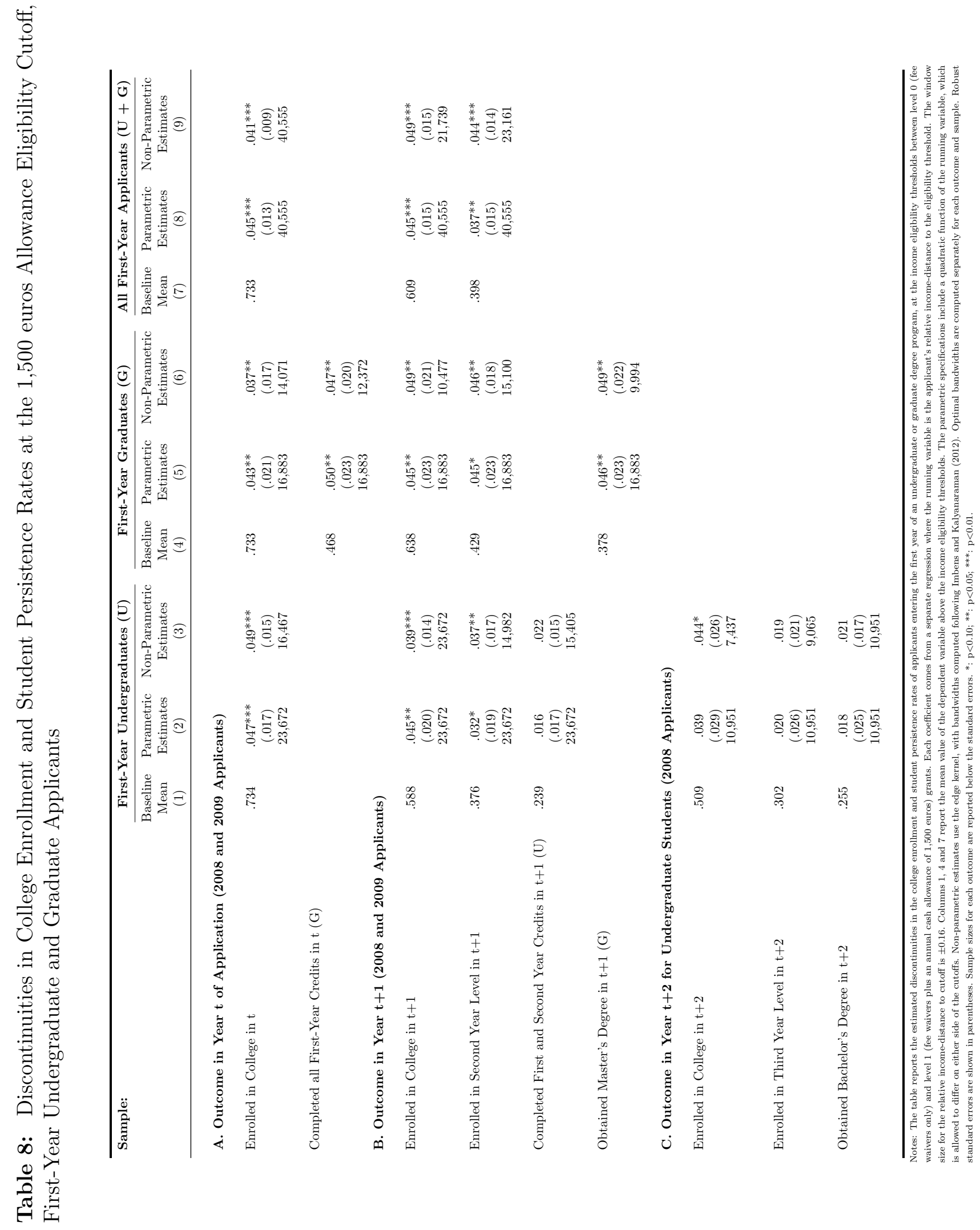




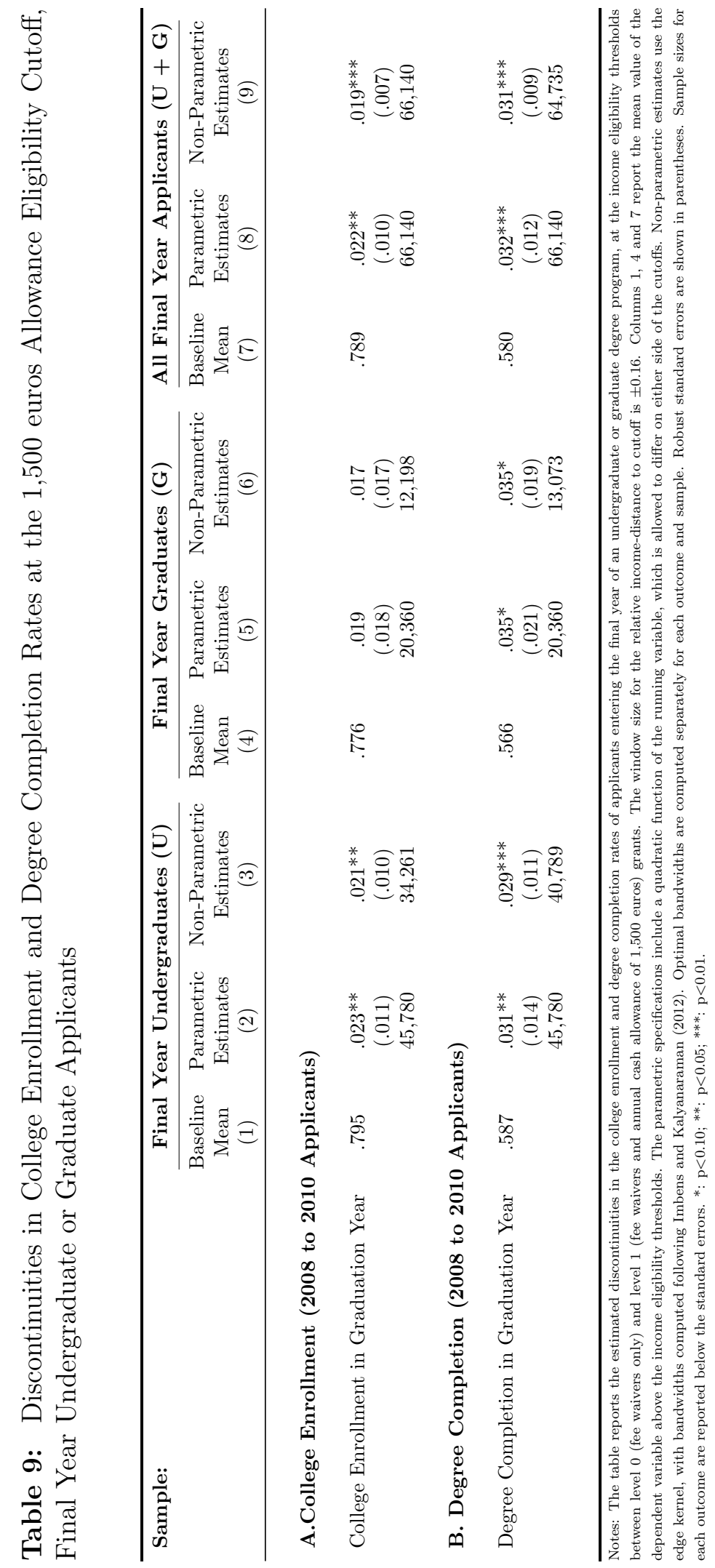

